\title{
Urquhart and Probability: The Transition From Librarianship to Library and Information Science
}

\author{
Stephen J. Bensman \\ LSU Libraries, Louisiana State University, Baton Rouge, LA 70803. E-mail: notsjb@Isu.edu
}

In this article, I analyze the role of Donald J. Urquhart in the creation of modern library and information science. Urquhart was one of the chief architects of information science in Britain and founder of the National Lending Library for Science and Technology (NLL), which evolved into the present-day British Library Document Supply Centre (BLDSC). In particular, I focus on the part played by Urquhart in the development of that branch of information science termed bibliometrics, the application of mathematical and statistical techniques to information phenomena, pursuing both historical and practical aims. The article is intended not only to trace the history of the probability distributions applicable to library use and other facets of human knowledge but also to demonstrate how these distributions can be used in the evaluation and management of scientific journal collections. For these purposes, the paper is divided into three parts of equal importance. The first part is statistical and establishes the theoretical framework, within which Urquhart's work is considered. It traces the historical development of the applicable probability distributions, discussing their origins on the European continent and how Continental principles became incorporated in the biometric statistics that arose in Britain as a result of the Darwinian revolution. This part analyzes the binomial and Poisson processes, laying out the reasons why the Poisson process is more suitable for modeling information phenomena. In doing so, it describes key distributions arising from these processes as well as the various tests for these distributions, citing the literature that shows how to conduct these tests. Throughout the discussion, the relationship of these distributions to library use and the laws of information science is emphasized. The second part of the article analyzes the pioneering role of Urquhart as a conduit for the entry of these probability distributions into librarianship, converting it into library and information science. He was the first librarian to apply probability to library use, utilizing it not only to establish and manage the scientific journal collections of the NLL but also to evolve his Law of Supralibrary Use. Urquhart's work is portrayed within the context of a general trend to adopt probabilistic methods for analytical purposes, and a major premise of this article is that his

Received August 27, 2003; revised January 13, 2004; accepted February 16, 2004

(C) 2004 Wiley Periodicals, Inc. • Published online 10 November 2004 in Wiley InterScience (www.interscience.wiley.com). DOI: 10.1002/asi.20108 law and the probabilistic breakthrough, on which it was based, were most likely in Britain, which was one of the few countries not only to develop but also maintain the necessary scientific preconditions. The third-and concluding section-discusses how Urquhart's Law forces a probabilistic reconceptualization of the functioning of the scientific journal system as well as the law's practical implications for journal sales, collection evaluation and management, resource sharing, and the transition from the paper to the electronic format.

\section{The Scientific Foundations}

During the twentieth century, Britain played a major role in two scientific revolutions that have now begun to converge. This convergence has led to the development of a theory of probability that is applicable to the production, use, and evaluation of human knowledge. Most of this development was focused on scientific information. The first of these revolutions was the biometric revolution, which led to the creation of modern inferential statistics. Building on foundations laid on the European continent, British statisticians began to create causal models and techniques for analyzing the skewed distributions that underlie many biological and social phenomena. The second revolution was the bibliometric revolution, a major feature of which was the discovery that the frequency distributions underlying information data are highly skewed. A major figure linking these two revolutions was Donald J. Urquhart, founder of the National Lending Library for Science and Technology (NLL), which evolved into the present-day British Library Document Supply Centre (BLDSC). The purpose of this article is both historical and practical, in that it will explain the probabilistic breakthrough of the biometric revolution, elucidate Urquhart's role as a conduit for this breakthrough into library and information science, and demonstrate the implications of Urquhart's work for the evaluation and management of scientific journal collections.

\section{Indeterminism, Probability, and Fuzzy Sets}

A major theme in the history of science, particularly in the twentieth century, was the transition from determinism to 
indeterminism. Kosko (1993, pp. 93-94) identifies as two key events of the early twentieth century in this transition Bertrand Russell's rediscovery of the classical Greek paradoxes at the foundation of modern mathematics and Werner Heisenberg's uncovering of the "uncertainty principle" in quantum physics. The development of inferential statistics can be considered part of this transition from determinism to indeterminism. Simply stated, the aim of scientific research became not to define mathematically a precise point but to determine statistically the amount of error in the definition of this point or the range within which this point could possibly lie. With respect to library and information science, two of the more important forms of this transition from determinism to indeterminism were probability and fuzzy sets. These two forms can be considered as closely interconnected. Probability is basically concerned with the distribution of occurrences over the elements of a set, whereas fuzzy set theory is concerned with the proportion of membership of the elements in the set-or the rate at which the occurrences should be allocated to these elements. The close interlock between probability and sets determines the central importance of Bradford's Law of Scattering in library and information science. This law is concerned with the distribution of articles on a given subject across journals in a set. In return, these articles define a subject set, and their distribution can serve as a measure of the proportion of membership of the journals in this subject set. Bensman (2001a) has demonstrated that, properly conceived, Bradford's Law of Scattering is a mathematical description of a probabilistic model for the formation of fuzzy sets and thus incorporates both forms of indeterminism in library and information science.

The probability theory applicable to human knowledge evolved out of a scientific revolution in the Kuhnian sense. This revolution involved the overthrow of what I call the "normal paradigm." The normal paradigm is the theory that all observations or occurrences in nature and society follow the normal distribution. Formulated almost simultaneously at the turn of the nineteenth century by Carl Friedrich Gauss and Pierre Simon Laplace, the normal distribution was originally developed as a law of error in astronomical observations. It is based on the concept that the best estimate of an astronomical point is the mean of the observations, around which all the observations are symmetrically distributed in a manner mathematically described by the famous bell-shaped curve. This law of error became confounded with a law of natural variation, according to which all natural and social phenomena conform to this distribution. The primary culprit in the normal paradigm was the Belgian scientist, Adolphe Quetelet, who invented the theory of the l'homme moyen, or the average man. According to this theory, all human physical and social characteristics - height, chest size, marriages, suicides, crimes, and the like-are normally distributed. Central to Quetelet's thinking is the idea that the mean is the best measure of any phenomenon, and the distribution of the observations around this point is the result of error. This emphasis on the mean as the summation of the essence of phenomena was to be a hallmark of statistics on the European continent.

For most of the nineteenth century the normal paradigm was regnant. However, it began to be noticed that many phenomena-particularly social and biological ones-are not symmetrically distributed around a mean, but are asymmetrically distributed in a positively skewed manner that results in the bulk of the occurrences being accounted for by a relatively few members of a given set. It was this realization and its incorporation into probability theory that lay at the basis of the scientific revolution out of which library and information science evolved.

\section{Continental Lexian Statistics}

Asymmetric distributions of the library and information science type are the result of basically two stochastic processes: inhomogeneity and contagion. These two processes correspond to two phases of the scientific revolution, leading to the overthrow of the normal paradigm. The first phase concerned inhomogeneity. It began in Germany, originating in the work of the economist and statistician, Wilhelm Lexis. In the late 1870s Lexis developed his theory in a series of articles and books that laid the foundations of what came to be called Lexian statistics. Outside of Lexis himself, the most important representative of the Lexian school of statistics was his student, Ladislaus von Bortkiewicz. Lexian statistics were introduced to the English-speaking world mainly by two British economists, Francis Ysidro Edgeworth and John Maynard Keynes. Keynes (1921, p. 394) called Lexis and his followers the "German school," noting that it included not only Germans but also "those Russians, Austrians, and Dutch who usually write in German, and are in habitual connection with the German scientific world." To these should be added certain Scandinavians such as C.V.L. Charlier, the Swedish astronomer, who is considered the founder of the Scandinavian school in statistical theory. Lexian statistics also found a following in the United States. Some of the most cogent codifications of Lexian statistics in the English language were provided by Arne Fisher (1922) and Henry Lewis Rietz (1924, 1927). Arne Fisher was a Danish-American actuary, whose major contribution was to introduce American mathematicians to the work of the great Scandinavian statisticians, whereas Rietz was a professor of mathematics at the University of Iowa and the founder of the Institute of Mathematical Statistics.

The normal distribution was derived from the binomial distribution, and the latter distribution is the main focus of Lexian statistics. One consequence of this focus is to emphasize the close relationship of the arithmetic mean to probability. Rietz (1927, p. 16) noted that Continental European statisticians often employed a concept he termed the "mathematical expectation of the experimenter or the expected value of the variable," stating that the mathematical expectation of a variable and its mean value from the appropriate theoretical distribution are identical. The binomial 
distribution results from the repeated drawings of a sample of size $s$ from the population of the universe or set under analysis. Calculation of the frequency of the specific number of successes or occurrences is done with an equation that is built on the expansion of $(p+q)^{s}$, where $s$ is the sample size, $p$ is the probability of success, $q$ is the probability of failure, and $p+q=1$. The key binomial parameter is $p$, and the arithmetic mean of the binomial distribution can be calculated either by dividing the total number of attempts into the number of successes or by multiplying the size of the sample $s$ by the probability $p$ of success. Two conditions are required for the binomial distribution. The first concerns inhomogeneity or rather the lack of it. For the binomial distribution to arise, the underlying probability $p$ must remain constant from sample to sample, indicating a set governed by a single underlying probability. The second condition relates to contagion. This condition stipulates that samples must be mutually independent in the sense that the result of a given sample does not depend in any significant manner on what had happened in previous samples.

Lexian statistics involves testing for the binomial by comparing the variance calculated directly from the data of a set to the variance theoretically expected under the conditions of the binomial. The comparison is accomplished by calculating the Lexis Ratio, which is done by dividing the actual standard deviation of the set by its theoretical binomial standard deviation. If the ratio is 1 , the actual variance is equal to its theoretical binomial variance. In Lexian theory this means that the distribution has "normal" dispersion, indicating a homogeneous set governed by a single probability and with occurrences that are independent from each other.

If the resulting ratio is significantly greater than 1 - or the actual variance is greater than the theoretical binomial variance- then Lexian theory considers the distribution as having a hypernormal or supernormal dispersion. We are then dealing not with a binomial distribution but with a Lexian distribution. A Lexian distribution can be defined as a distribution arising not from a homogeneous set governed by a single underlying probability but from a composite set consisting of subsets having different underlying probabilities. Lexis and his followers found most social distributions to be of the Lexian type. This certainly is true of library and information science because of the operation of Bradford's Law of Scattering, which mandates that every set will be a composite of subsets from various subject fields.

However, according to Lexian theory, if the Lexis Ratio is significantly less than $1-$ or the actual variance is less than the theoretical binomial variance-then the distribution has subnormal dispersion. Lexian theory considers this condition as characteristic of the Poisson distribution. This distribution is named after Siméon-Denis Poisson, who derived it from the binomial distribution in a book published in 1837 on French judicial decisions. The Poisson distribution arises as a limit of the binomial, when the size of the sample $s$ rises to infinity and $p$ approaches zero. Therefore, the Poisson results when occurrences become relatively infrequent. It therefore has a much lower mean, and concomitantly lower variance, than the binomial. However, the Poisson distribution requires the same two conditions as the binomial: equiprobability and independence of trials. Although the Poisson distribution was mathematically derived by its French eponym, its real importance is a consequence of the work of Bortkiewicz. Haight (1967, pp. 113, 115) states that Bortkiewicz was the first to grasp the statistical significance of the Poisson distribution and that, although Poisson may have discovered the mathematical formula, Bortkiewicz discovered the probability distribution. Bortkiewicz made the Poisson the basis of his Law of Small Numbers, which he formulated in a pamphlet published in 1898. This pamphlet contains his famous analysis of the distribution of the number of soldiers kicked to death by horses in 14 Prussian army corps in the 20-year period 1875-1894. Winsor (1947) has carefully analyzed this pamphlet, using modern notation and translating the key sections. So closely related is Bortkiewicz's Law of Small Numbers to the Poisson distribution that the two are often confused with each other. However, this confusion arises from ignorance of the Lexian basis on which Bortkiewicz proceeded. Stated in its simplest form, what Bortkiewicz's Law of Small Numbers posits is that, if one restricts the field of observation in a given set to that end of the distribution where occurrences are infrequent, the resulting distribution will be the Poisson distribution, no matter what the differing probabilities of the various subsets composing the set under analysis. This law is of enormous significance in library and information science, for it means that if one restricts the field of observation to those items in a library or database infrequently used, no matter what their subject class, one can expect that the mean use of the set thus defined will be low, and no individual item's use will deviate too far from this mean. Such knowledge is extraordinarily helpful in choosing items for weeding or relegation.

Bortkiewicz's Law of Small Numbers is probably the first example of a simple Poisson model. To understand a simple Poisson model, one first has to know the difference between the binomial and the Poisson process. It was stated earlier that the binomial distribution is based on samples of a given size being repeatedly drawn from a population under investigation. Therefore, it is the result of a sequence of independent experiments or discrete trials. In contrast, the Poisson distribution is based on mean rate of occurrencetechnically called lambda—over some continuum such as time or space-in the Bortkiewicz study, years and army corps. These different bases of origin lead to three major distinctions between the binomial and the Poisson process. First, the binomial process entails independent experiments that are separated in time, whereas the Poisson process results from a rate of occurrence continuously over time and area. Second, the key binomial parameter is $p$, which is calculated by dividing the number of successes by the number of attempts, whereas the key Poisson parameter is lambda, or mean rate of occurrence over a defined continuum. Third, the Poisson process is much more flexible than the binomial. 
This characteristic was described by Newbold (1927) as follows:

The property of the Poisson limit which makes the series so applicable to time and space problems, is that the sum of a set of numbers, each following a separate Poisson series (about different means) is itself a Poisson series. We can thus split up our time or space units into smaller ones, divide our cells, or change our periods of exposure, or sum the records of separate individuals into records of groups, and each of the single sets as well as the sum of the whole, will give a Poisson series. (pp. 492-493)

Thus, while the binomial is derived by a rather rigid procedure of drawing samples of fixed sizes from a population, the Poisson allows great flexibility in organizing data into sets for purposes of analysis.

These differences make the Poisson process more suited to research in library and information science than the binomial one. In this field it is often impossible to conduct independent, repeatable experiments, and one must rely on data resulting from occurrences over some continuum. Moreover, to calculate the binomial $p$, one must know not only the number of successes but also the number of failures, and this is a major drawback to applying the binomial in library and information science. For example, while it is easy to count how many times a book did circulate, it is impossible to count how many times a book did not circulate. In contrast, the mean rate of occurrence is easily calculated from the observed number of occurrences. Moreover, the greater flexibility in defining data into sets is a huge advantage in a field, where experiments are not repeatable, sets are fuzzy, and research surprises are frequent. However, both the binomial and the Poisson processes require the same two conditions: equiprobability and independence. Bortkiewicz's army corps did not fully meet these requirements, because the 14 army corps had differing mean accident rates and therefore different underlying probabilities, and this is the significance of the Law of Small Numbers from the Lexian viewpoint. One of the hallmarks of the simple Poisson model or distribution is that lambda, the mean, and the variance are all equal to each other.

\section{British Statistics}

The second phase of the scientific revolution leading to the overthrow of the normal paradigm took place in Britain. This phase of the revolution established the theoretical foundations for contagion. In their inception British statistics were an offshoot of the Darwinian revolution, and their initial development was stimulated by the problem of evolution and the inheritance of biological characteristics. This research interest had a social focus in that a major aim of the creators of British statistics was improvement of the human species-an aim that became expressed in the eugenics movement. The eugenic purpose of British statistics resulted in a basic difference of British statistics from Continental statistics. Whereas Continental statistics were focused primarily on the mean, British statistics were mainly interested in variance and particularly in how much change in a particular characteristic of the members of one set were the result of changes of this characteristic in the members of another set. This interest was the basis for the development of the techniques of correlation and regression by British statisticians. In their development British statistics can be divided into two stages, each of which had its own institutional center. The first stage can be roughly dated from 1860 to 1920. Its main locus was University College London, where Frances Galton and Karl Pearson did their work. The second stage lasted approximately from 1920 to 1950 and was centered at the Rothamsted Experimental Station, the agricultural research institute just north of London. Here Ronald A. Fisher did his pioneering work in the 1920s that completed the foundations of British inferential statistics.

British statistics ultimately came to dominate in the United States, and each stage in the development of these statistics had its own institutional entry point. Columbia University served as the main conduit for the first stage. Camic and Xie (1994) have analyzed the role of this institution in the evolution of American statistics during the crucial period 1890-1915. In their treatment of this topic Camic and Xie divide statistics into the "Continental approach," which they characterize as the "science of averages," and the "British approach," which they denote as the "science of variation." The adoption of the new statistical techniques at Columbia was concentrated in the social sciences, and Camic and Xie classify the four main innovators according to the Continental/British scheme in the following manner: the Continental approach has James McKeen Cattell in psychology and Franklin H. Giddings in sociology; the British approach has Franz Boas in anthropology and Henry L. Moore in economics. Even though Camic and Xie classify Cattell as using the Continental approach, the psychologist was evidently influenced by the British statisticians, having studied for a period under Galton. This is a fact not without interest for the history of library and information science. One of Galton's primary interests was the inheritance of human intelligence. Galton (1874) even wrote a book on this process in respect to English scientists. Cattell (1906; 1910) pursued this interest of Galton, developing the first quality ratings of U.S. scientists and university science departments. Later at Columbia University, Robert K. Merton followed in Cattell's footsteps and founded the discipline of the sociology of science, which has proven to be extremely important for library and information science.

Iowa State College in Ames, which became Iowa State University in 1959, was the main American entrepôt for British statistics as developed by Fisher at Rothamsted during the second stage. Like Rothamsted, Iowa State was a major agricultural research center. The person at Iowa State most important for the importation of Fisher's statistical concepts and methods was George W. Snedecor, who was instrumental in bringing Fisher to Ames as a visiting professor twice, in 1931 and 1936. One of the primary vehicles for the transmission of British statistical methods into the 
United States was Snedecor's textbook Statistical Methods, which went through eight editions from 1937 to 1989. The early editions' full title was Statistical Methods Applied to Experiments in Biology and Agriculture. Starting with the fifth edition in 1956, Snedecor's textbook began to be coauthored by William G. Cochran, who came to Iowa State as a professor in 1939 after starting his career at Rothamsted. The Snedecor and Cochran (1989) textbook became one of the most authoritative codifications of the statistics of the British biometric school.

The crucial event in the first stage of the development of British statistics was the rejection of the normal paradigm. It took the following course. Galton, a first cousin of Charles Darwin, had learned the normal paradigm from Quetelet and had used it to construct a probabilistic model of evolution. Galton (1892/1925, pp. vii-xxvii) gave a succinct account of the development of this model in the prefatory chapter to the second edition of his book Hereditary Genius published in 1892. According to this model, the measurements of a given characteristic of a species center around a mean, which forms the racial center, and deviations from this mean are considered to be error. If the species is stable, there is a process of regression to the mean, by which the offspring of parents deviating far from this mean will move back toward the mean. However, as a result of environmental conditions, there can appear "sports," whose deviation from the mean is not error but part of the formation of a new species with a different mean or racial center. Thus, evolution was envisaged by Galton as a shift in underlying probabilities resulting in a shift of means. A University College London zoologist, Walter Weldon (1890, 1893), tested Galton's theory and found that certain crabs in a sample of crabs from the Bay of Naples had a frontal breadth much larger than the others, forming an asymmetric distribution of frontal breadths. Weldon hypothesized that the bigger crabs were sports, but proof of this hypothesis required that the asymmetric curve be broken down into two normal curves. This was beyond the mathematical abilities of Weldon, who turned for aid to Karl Pearson, then teaching applied mathematics at University College London.

Weldon's problem caused Pearson to change the direction of his career and concentrate on the development of statistical techniques. This change was marked by his beginning to author in the mid 1890s a series of memoirs on the mathematical theory of evolution. Of these memoirs the first two are of the utmost importance in the development of the probabilistic theory applicable to human knowledge. In the first memoir Pearson (1894) mathematically demonstrated that homogeneity did not necessarily result in a symmetric distribution and that Weldon's crabs were of the same species but with a differentiated frontal breadth. With this finding Pearson undercut one of the main bases of the normal paradigm.

However, Pearson (1895) made his greatest contribution to the probability theory applicable to human knowledge in his second memoir, which had the portentous subtitle, "Skew Variation in Homogeneous Material." He began this memoir by pointing out that asymmetric frequency curves may arise from two distinct classes of causes. The first such class is when the material measured may be heterogeneous in that it consists of a mixture of two more homogeneous materials. According to Pearson, the treatment of this class of frequency curves requires the breaking up of the original curve into component parts or simple frequency curves. Without stating it, he was actually describing here the causation underlying the Lexis distribution and the Lexian approach to handling such a distribution. Pearson wrote that he had dealt with a special case of this type of compound distribution as a sum of two normal curves in his first memoir on Weldon's problem of the Naples crabs.

In his second memoir Pearson (1895) did not discuss the above class of frequency curves but instead focused on a second class of asymmetric curves that arise "in the case of homogeneous material when the tendency to deviation on one side of the mean is unequal to the tendency to deviation on the other side" (p. 344). He noted that such curves are found in many physical, economic, and biological investigations. In analyzing this class of distributions Pearson developed the first five of his mathematical models of asymmetric frequency curves. Pearson's system of frequency curves ultimately came to number 12 . What is particularly significant is that he derived his system of frequency curves off the hypergeometrical series, which Pearson (1916, pp. 429-430) stated that he deliberately chose because it violated the three fundamental axioms of the normal distribution: (1) the equality in frequency of plus and minus errors of the same magnitude from the mean is replaced by an arbitrary ratio; (2) the number of contributory causes is no longer indefinitely large; (3) and the contributions of these causes are no longer independent but are instead correlated. The last condition was a direct violation of the primary condition of the binomial as well as the Poisson distribution for independence of trials. It incorporated the concept of contagion, whereby the happening of an event changes the probability of its happening again - a process inherent in library use.

Of the five asymmetric frequency curves Pearson (1895) presented in his second memoir on skew variation in homogeneous material, two proved to be of the utmost importance for the development of the probability theory applicable to human knowledge. The first of these was Type I, which Pearson characterized as follows: "Limited range in both directions, and skewness" (p. 360). Later Pearson (1901) split Type I, allocating some of its distributional coverage to Type VI. These curves laid the bases for two forms of the beta distribution. The other of Pearson's five initial frequency curves important to the development the probability theory of human knowledge was his Type III, which is also called the gamma distribution. Pearson (1895) described this curve thus: "Limited range in one direction only and skewness" (p. 360). Pearson emphasized the importance of the Type III curve by graphically demonstrating how well it modeled the positively skewed frequency distributions often found in reality. Of his system of asymmetric frequency curves, Type III is the one that best describes the frequency distributions that usually appear in library and information science. 
As part of his work with probability distributions, Pearson (1900) developed a method for testing how well an actual frequency distribution matches a theoretical frequency distribution. He based his method on the chi-squared distribution, which is a particular case of his Type III or gamma distribution. The test is called the chi-squared goodness of fit test, and it compares the frequencies actually observed to the frequencies theoretically predicted. In essence, Pearson's chi-squared goodness of fit test compares the actual variance of a set of observations to the variance expected on the assumption of a given theoretical distribution and in this respect is similar to the Lexis Ratio.

\section{The Melding of Continental Lexian and British Statistics}

The intellectual breakthroughs of both Continental Lexian and British statistics in the latter part of the nineteenth century paved the way for the development of theoretical probability distributions that can model the two basic stochastic processes-inhomogeneity and contagionoperative in the skewed frequency distributions often found in library and information science. In respect to inhomogeneity, the basic form of the probability models was the compound distribution. A compound distribution arises when the parameter of the distribution itself $-p$ in the binomial and lambda in the Poisson-is itself a random variable following its own probability distribution. Here it should be emphasized that inhomogeneity in library and information science takes two forms, each of which corresponds to one of the above statistical schools. The first can be termed Lexian and is a result of Bradford's Law of Scattering, which causes library and information science sets to be composites of various subject subsets with differing underlying probabilities and therefore different means. The second form can be called Pearsonian, because it is the probabilistic inhomogeneity of members of homogeneous sets that causes their distribution to be asymmetrically skewed. From this it can be seen that library and information science sets are extremely complex, especially because they lack clear demarcations and are therefore fuzzy as a function of Bradford's Law.

Development of the probability models described earlier was accomplished by the melding of the ideas of the Continental and British schools. Prior to World War I the Continental and British schools of statistics evolved independently from each other, and Keynes (1921, p. 394) noted that during this period among the British only Edgeworth had manifested a close acquaintance with the statistics of the Continental school. However, this changed after World War I as a result of the rise of totalitarian regimes on the European mainland. These regimes devastated Continental statistics, forcing its leading representatives like William Feller, George Pólya, and Richard von Mises to take refuge primarily in the United States.

Of the two fundamental distributions- the binomial and the Poisson-discussed earlier, it was the Poisson that was the first to be used as a basis for the creation of stochastic models capable of representing the random processes underlying the skewed distributions often found in library and information science. This distribution became intimately connected with the negative binomial distribution (NBD). Pearson (1916, p. 454) became interested in the distributional potential of the negative binomial, which he defined as having the form $(p-q)^{-s}$, where $p-q=1$. The NBD is a distribution of particular significance for library and information science, because it can arise from both stochastic processes-inhomogeneity and contagion-that affect frequency distributions in this field. Important as it is, the negative binomial can only be considered a representative distribution in library and information science. This is because precise mathematical fits of data to given theoretical distributions require crisp sets, which tend to be rare in library and information science. Nevertheless, it is in the history of the negative binomial distribution that one can best see the theoretical development of the stochastic processes affecting distributions in library and information science.

The Poisson distribution entered British statistics through William S. Gosset or "Student" (1907), who derived it independently as a limit of the binomial in a paper on error in counting yeast cells with a haemacytometer. Ronald A. Fisher (1925, pp. 57-59) cited "Student's" paper as establishing the importance of the Poisson in biological research and used data from it to demonstrate this distribution in his classic textbook. Fisher himself thought that "among discontinuous distributions the Poisson Series is of the first importance" (p. 57). In a crucial paper "Student" (1919) explored "the general question of what effect various departures from the conditions which lead to Poisson's Law have on the resulting statistics, and especially which conditions lead to positive and which to negative binomials when the exponential [i.e., the Poisson] might at first sight be expected" (p. 211). After analyzing the question in terms of the occurrence of different numbers of individuals in divisions of time and space, "Student" enunciated the following important principles:

We have now shown that a population which might be expected at first sight to follow Poisson's law

(1) Will do so if the only deviation from the ideal conditions is that the chances of different individuals falling into the same division are not equal, as long as these chances are all small.

(2) If in addition to this the chances of some individuals are large a positive binomial will fit the results better than the exponential.

(3) If the different divisions have different chances of containing individuals, as is usual, a negative binomial will fit the results better than the exponential, except in so far as (2) may interfere.

(4) If the presence of one individual in a division increases the chance of other individuals falling into that division, a negative binomial will fit best, but if it decreases the chance a positive binomial.

Generally speaking (3) is the operating deviation from Poisson's conditions and accordingly most statistics give negative binomials. (p. 215) 
Principle (1) is a restatement of Bortkiewicz's Law of Small Numbers; principle (3) is the basis of the inhomogeneity model of the NBD; and principle (4) sets forth the conditions of the contagion model. "Student" himself gave priority to the inhomogeneity model.

The accepted inhomogeneity model of the NBD was developed by Major Greenwood and George Udny Yule (1920) on the basis of industrial accident statistics. As later stated by Greenwood (Newbold, 1927, pp. 536-537), their interest in accident statistics was stimulated by the needs of the Royal Flying Corps, which during World War I had to make decisions on whether to allow a pilot having an accident to fly again. To eliminate the question of unequal exposure to risk, they decided to analyze trivial accidents among female workers in munitions factories. Greenwood and Yule developed a compound Poisson model, which can be explained simply in the following fashion. Each female worker was considered as having a mean accident rate over a given period of time or her own lambda. Thus, the accident rate of each female worker was represented by a simple Poisson distribution. However, the various female workers had different underlying probabilities of having an accident and therefore different lambdas. Greenwood and Yule posited that these different lambdas were distributed in a skewed fashion described by Pearson's Type III or gamma distribution, and therefore certain workers had a much higher accident rate than the others and accounted for the bulk of the accidents. They found that this model fitted the data very well. Given its construction, the Greenwood and Yule form of the negative binomial distribution is called the gamma Poisson model. This form of the negative binomial distribution can be considered as modeling the probabilistic inhomogeneities of members of a homogeneous set, and it used the gamma distribution as the mathematical description of accident proneness.

Greenwood and Yule (1920, pp. 258-264) experimented with a contagion model of the NBD in their accident paper, whereby the happening of an event to a given member of the set not only improves the chances of that member but also militates against the chances of the other members of the set not yet experiencing the event to experience it. However, they were not successful in developing a practicable model for this. The real connection of the negative binomial with contagion was made in Zurich by George Pólya together with his student F. Eggenberger. In a classic paper Eggenberger and Pólya (1923/1984) derived what is termed the Pólya distribution, from an urn scheme that modeled contagion. This scheme involved drawing balls of two different colors from an urn and not only replacing a ball that was drawn but also adding to the urn a new ball of the same color. In this way numerous drawings of a given color increased the probability of that color being drawn and decreased the chance of the other color being drawn. Eggenberger and Pólya tested their model against the number of deaths from smallpox in Switzerland in the period 1877-1900.

The Pólya distribution is extremely malleable, and a number of other distributions arise from it as the parameters change. One such distribution is the NBD. In a key paper Feller (1943) noted this, stating that Eggenberger and Pólya had independently rediscovered a distribution originally found by Greenwood and Yule. Feller then analyzed the different stochastic bases of the Pólya-Eggenberger and Greenwood-Yule derivations of the negative binomial. According to Feller, the Pólya-Eggenberger form was a product of "true contagion," because each favorable event increases (or decreases) the probability of future favorable events, whereas the Greenwood-Yule model represented "apparent contagion," because the events are strictly independent and the distribution is a consequence of the inhomogeneity of the population. Feller succinctly summed up the stochastic difference of the compound Poisson form of the NBD from the contagious form:

It is well known that the simple Poisson distribution describes mutually independent events; in other words, with a Poisson distribution the numbers of events in two nonoverlapping time intervals are uncorrelated and the occurrence of an event has no influence on the probability of occurrence of further events. Accordingly, the compound Poisson process also applies to independent and not contagious events. With really contagious events (as, for example, with epidemics) the occurrence of each event increases (or decreases) the probability of further events. (p. 398)

Given that Greenwood-Yule and Pólya-Eggenberger reached the NBD on different stochastic premises-the first on inhomogeneity, the second on contagion-Feller posed the conundrum that one therefore does not know which process is operative when one finds the negative binomial, and he pointed out that this also applies to other types of contagious distributions such as those developed by Jerzy Neyman in entomology and bacteriology. Feller's conundrum certainly holds true for library and information science. For example, one does not really know whether a given scientific journal circulates more than others, because it is qualitatively or quantitatively different, because patrons have used and recommended it, or because these two factors are operating interactively. This conundrum is not unique to Feller but is inherent in the problem of determining the causation of asymmetric distributions. In his pioneer paper on skew variation in homogeneous material Pearson (1895, p. 394) admitted that he had not been able to develop a way to distinguish by his mathematical method a skew curve of the homogeneous type from a compound curve, if there were no reason a priori to suspect the data as being a mixture of different components.

The close interconnection of inhomogeneity and contagion in the type of asymmetric frequency distributions found in library and information science was reinforced by the further theoretical development of the Lexis distribution. Lexis distributions are actually mixtures of binomial distributions, and these came to be modeled by the compound binomial distribution. Here, again, a key role was played by one of the asymmetric distributions pioneered by Pearson. However, unlike the compound Poisson form of the NBD, where 
lambda follows the gamma distribution, the most fully studied form of the compound binomial distribution used the beta distribution as the "mixing distribution" for the binomial parameter $p$. Moran (1968, p. 76) as well as Johnson and Kotz (1969, p. 79) described the beta distribution as the "natural" distribution for $p$ in the compound binomial distribution, and therefore this form of the compound binomial is sometimes named the beta binomial distribution (BBD). However, similarly to the negative binomial, the BBD can arise in a number of different ways, and therefore it also has a number of different names. Two of these are the negative hypergeometric distribution and the Pólya distribution. The latter name results from the fact stated by Patil and Joshi (1968, p. 30) that the BBD is one form that the Pólya distribution can take. Griffiths (1973) states that the negative binomial is the limiting form to the beta binomial in an analogous manner as the Poisson serves as a limit to the binomial. Haight (1978, p. 158) describes the beta binomial as "the discrete time analog" of the compound Poisson form of the negative binomial, because the events are counted in short time periods so that only a success or failure is recorded.

A major step in the integration of Continental Lexian statistics with British statistics was taken by R.A. Fisher. In his classic textbook Fisher (1925, pp. 60-64, 71-73) presented two tests - one for the binomial, the other for the Poissonthat used Pearson's chi-squared distribution as an index of dispersion. An examination of the equation for chi-squared in the binomial test reveals it to be based on a comparison of the actual variance of a set of data to its theoretical binomial variance. The relationship to the Lexis Ratio is obvious, and Fisher himself stated, "In the many references in English to the method of Lexis, it has not, I believe, been noted that the discovery of the distribution of $\chi^{2}$ in reality completed the method of Lexis" (p. 79). He then outlined a method by which a given chi-squared could be transformed into its equivalent Lexis Ratio. Fisher's equation for chi-squared in his index of dispersion test for the Poisson is based on a comparison of the actual variance of a set to the arithmetic mean of the set. However, because under the conditions of the Poisson, the mean is equal to the variance, this test is also a comparison of actual variance to theoretical variance.

Fisher's index of dispersion tests were further developed by Cochran (1954), who placed them within the system of hypothesis testing that is the standard method in statistics today. This system was created by Neyman and Pearson's son Egon but was never accepted by Fisher himself. It involves null and alternative hypotheses. With respect to Fisher's binomial test, Cochran stated two main reasons for departures from the binomial:

(1) the data follow a different frequency distribution, usually with a larger variance (or the probabilities of success $p_{i}$ show some kind of random variation from observation to observation).

(2) the probabilities $p_{i}$ are affected by a systematic source of variation. (p. 426)
Cochran here is actually stating the conditions for a onetailed test, for both his reasons lead to the actual variance being greater than the theoretical binomial variance with the first reason reflecting inhomogeneity, and the second, contagion. However, given Fisher's linking of his binomial index of dispersion test with the Lexis Ratio, one can define the hypotheses for his binomial index of dispersion test in accordance with Lexian theory and its further development through the compound binomial distribution. This would lead to a two-tailed test. The null hypothesis would be the binomial distribution. If the actual variance is significantly less than the theoretical binomial variance, the alternative hypothesis is that the distribution has the subnormal dispersion indicative of the Poisson distribution; if the actual variance is significantly greater than the theoretical binomial variance, the alternative hypothesis is that the distribution has the supernormal dispersion characteristic of the Lexian distribution or a compound binomial such as the beta binomial. Thus, although Cochran's second reason indicates the operation of contagion, Fisher's binomial index of dispersion test can be considered from the Lexian viewpoint a test for whether a set is homogeneous or composed of subsets governed by differing probabilities. The latter case is the most frequent one in library and information science, where Bradford's Law of Scattering mandates that each subject set will be composed of subsets from various subject fields.

In discussing Fisher's index of dispersion test for the Poisson, Cochran (1954, p. 421) stated two common reasons for data not fitting this distribution: (1) the data follow some other single distribution like the negative binomial or one of the "contagious" distributions, and (2) the means of the observations follow some systematic pattern. He explained the latter case by what might happen when samples are taken over several days: The means might be constant within a day but vary from day to day, or they might exhibit a slow declining trend. Once again Cochran is setting conditions of a one-tailed test, for in both these cases the actual variance would be higher than the theoretical Poisson variance. In contrast, Elliott (1977, pp. 40-44) proposes a two-tailed test. The null hypothesis here is the Poisson distribution. If the variance is significantly less than the mean, Elliott defines the alternative hypothesis as "a regular distribution"; if the variance is significantly greater than the mean, he states the alternative hypothesis as "a contagious distribution." According to Elliott (1977, pp. 46, 50-51), the positive binomial distribution is the approximate mathematical model for a regular distribution, whereas the negative binomial is the most useful mathematical model for the diverse patterns of contagious distributions.

Fisher's index of dispersion test for the Poisson is more applicable in library and information science than his index of dispersion test for the binomial. This is because the test for the binomial is based on comparing actual variance to theoretical binomial variance, whereas the test for the Poisson involves comparison of actual variance to the arithmetic mean. To calculate theoretical binomial variance, one has to estimate the binomial parameter $p$. As noted earlier, 
it is often not possible to estimate the binomial parameter $p$ in library and information science because of an inability to count nonoccurrences, but the arithmetic mean is easily calculated off the observed number of occurrences. However, these two index-of-dispersion tests can be considered virtually equivalent to each other particularly in library and information science. The Poisson index-of-dispersion test will capture the effects of inhomogeneity, whether it be the Lexian differences in the probability of subsets or the Pearsonian differences in the probability of members of homogeneous sets. One reason for the equivalence of these two tests in library and information science is that overall probability in this field is usually quite low. Snedecor and Cochran (1989, pp. 130-131) as well as Moroney (1956, pp. 125-127) prove that the binomial and the Poisson tend to approximate each other as $p$ becomes small. Moroney states as a rule that the Poisson can always be used as an approximation to the binomial whenever $p$ in the binomial is small and that the closer $p$ is to zero, the better the approximation.

\section{Urquhart and Information Science}

\section{Urquhart and His Scientific Milieu}

As in the case of modern inferential statistics, the British played a major role in the creation of information science and its development in the United States. This was particularly true in respect to that branch of information science called bibliometrics, which is the focus of this article. The term bibliometrics was first coined in Britain by Pritchard (1969), who defined it as "the application of mathematics and statistical methods to books and other media of communication" (p. 349). Pritchard invented this term at the urging of the famous British statistician, Maurice G. Kendall. The main locus for the rise of information science in Britain was the Science Museum Library (SML) in London, where S.C. Bradford did his work. Many persons were instrumental in the movement of information science from Britain to the United States, where it underwent significant changes in focus and emphasis, but two have special importance. One was Eugene Garfield, founder of the Institute for Scientific Information, who based his citation indexes on Bradford's Law of Scattering. Garfield carefully studied the proceedings of the 1948 Royal Society Scientific Information Conference and was heavily influenced by one of the main participants in this conference, J.D. Bernal. Bernal was a Communist, who emphasized the societal aspects of science, and this emphasis was continued by Garfield. Garfield formed a close relationship with Robert K. Merton, the Columbia University professor, who continued the work of Cattell at his institution by being the founder of the sociology of science. Merton, together with his students Harriet Zuckerman and Jonathan and Stephen Cole particularly analyzed the social stratification of science, which they considered to be based on a process they termed the Matthew Effect. This term was derived from the gospel of St. Matthew
(13:12), which states: "For whoever has, to him shall more be given, and he shall have an abundance; but whoever does not have, even what he has shall be taken away from him."

The other person of special importance in the transfer of information science from Britain to the United States was Derek J. de Solla Price. Like Cochran, Price was British, beginning his career in Britain but then moving to the United States. Price was born in London. He obtained his first doctorate in experimental physics from the University of London in 1946 and his second doctorate in the history of science from Cambridge University in 1954. In 1959 Price became a professor of history at Yale University, but his work and emphases always reflected his British origins. His research interests turned to bibliometrics, librarianship, and science policy. In this research he developed a close relationship with both Garfield and Merton.

Donald J. Urquhart was one of the chief architects of information science in Britain, emerging into prominence at the 1948 Royal Society Scientific Information Conference. During the main period of Urquhart's activity, the Poisson process and negative binomial had become firmly established in biology and were penetrating the social sciences. Of the biological applications of the negative binomial, the one most relevant to library and information science is its utilization in ecology to model distributions of plants and animals. Like a swamp, for example, libraries and other information databases can be conceptualized as environmentally inhomogeneous, and species of scientists may be thought to be like any other life form in that they tend to concentrate in areas environmentally most favorable to them, attracting others of their species. Thus, similarly to other life forms, the distribution of scientists can be modeled on the basis of the stochastic processes of inhomogeneity and contagion.

In the social sciences the negative binomial and Poisson distributions of its type serve basically as models of the zero sum game. To take the example of library use, for any given period there can only be so many library circulations. If certain items have a higher probability of circulating than others, these can only obtain this higher use at the expense of others having a lower or even zero use. In a paper read to the Study Section of the Royal Statistical Society Andrew Ehrenberg (1959) introduced the negative binomial to marketing as the model for consumer buying, with the purchases of individual buyers following the Poisson distribution in time and the average purchasing rates of the individual consumers being proportional to Pearson's gamma distribution. The applicability of Ehrenberg's model to library users is easily seen. A major landmark in the penetration of the Poisson process and the negative binomial into the social sciences was the publication of the textbook Introduction to Mathematical Sociology, by James S. Coleman (1964) of Johns Hopkins University. In a chapter entitled "The Poisson Process and Its Contagious Relatives," Coleman (pp. 291 and 299-308) argued for the appropriateness of the Poisson process for social phenomena and introduced the negative binomial as a "contagious Poisson." He later described one version of the contagious Poisson as modeling a 
system that behaves in accordance with the principle "them that has, gets" (p. 326). On this same basis Price (1976) pinpointed the importance of the negative binomial specifically for the sociology of science by describing it as the model of the double-edged Matthew Effect placed at the basis of the social stratification of science by Merton and his students. Urquhart played an important role in this development, because, by his own research and that sponsored by him, he was the first to introduce the Poisson process as a way to model the library use of scientific journals and to show how this process affected the use of these journals not only in individual libraries but also within a library system as a whole.

Urquhart's life represents a peculiar mix of science, industry, government, and librarianship. Born in 1909, he obtained an undergraduate degree in physics and a doctorate in metallurgy from the University of Sheffield in the late 1920s and early 1930s. His first job was in the research department of English Steel in Sheffield, and in 1938 he obtained a job at the Science Museum Library, when Bradford retired as its head. During World War II he worked at the Admiralty and then at the Ministry of Supply, where he became responsible for inspection procedures and a number of pay offices. As D. J. Urquhart (1990, p. 13) described his duties in his autobiography, the inspection procedures were linked to the bill paying arrangements, because a bill could only be paid for a consignment if it were certified as to quantity and quality. Following the war, he returned to the Science Museum Library, from where he moved in 1948 to the Department of Scientific and Industrial Research. As its name implies, the Department of Scientific and Industrial Research or DSIR was the agency through which the British government supported scientific research and ensured that industry used new scientific findings. In 1956 DSIR assigned Urquhart the task of creating the National Lending Library for Science and Technology (NLL), whose creation Urquhart had envisaged and advocated for a long time.

The course of Urquhart's life determined his approach toward librarianship. In his book The Principles of Librarianship D. J. Urquhart (1981, p. 25) stated that his training as a physicist had instilled in him an appreciation of the objective methods of the natural sciences. Moreover, according to him, an education in the exact sciences and an interest in mathematics had inclined him toward a love of precise calculations. However, D. J. Urquhart (1981, p. 25; 1990, pp. 6-7) wrote that this inclination was tempered by his experience in the Sheffield steelworks, which had taught him that strict scientific accuracy is usually not required and that it is necessary to convert the results of calculations into very simple rules. This made him an applied mathematician only interested in obtaining results that were near enough for practical purposes. From his World War II experience he learned the importance of cost effectiveness. In general, Urquhart was extremely conscious of the law of diminishing returns, which he formulated as one of his basic principles of librarianship thus (Urquhart, 1981, p. 74): "The best is the enemy of the good."

These attitudes became embodied in Urquhart's view of librarianship as a discipline. Thus, another of his basic principles of librarianship posits (Urquhart, 1981, p. 74): "Librarianship is an experimental science." However, for Urquhart, librarianship was a particular type of experimental science that had a specific purpose. This D. J. Urquhart (1986) clarified in an article that used the above basic principle as its title. Here he stated that when he was employed in the research department of the steelworks, he was concerned with helping his firm make better and cheaper products. Urquhart carried this attitude over to librarianship, where he thought that research should use the methods of the natural sciences to discover how to improve the flow of information and the cost-effectiveness of the existing arrangements. Therefore, for Urquhart, librarianship was an applied science. Moreover, in his view, librarianship was an inexact science, and he used Bradford's Law of Scattering as an example of this. According to Urquhart, there is no precise mathematical formula for Bradford's Law of Scattering that applies to all subject fields or to the same subject field at different times despite numerous attempts by Bradford himself and others to derive one. Moreover, he stated, even if there were a precise formula, it would have been of little value in determining, for example, which periodicals were needed by a special library to provide a particular percentage of the articles in its subject field. Urquhart pointed out that this lack of mathematical precision did not prevent Bradford's Law of Scattering from being of immense practical value. Among its consequences noted by him were the following: no special library could really expect to have a comprehensive collection in its field; it is really not sensible to try to place periodicals in subject pigeon holes; and finally, to be able to satisfy persons concerned with one subject field, it is necessary to have available in some way a comprehensive collection of periodicals. Urquhart's major accomplishment was to establish the institutional means for meeting this last dictate of Bradford's Law.

The above views on science and librarianship manifested themselves in Urquhart's utilization of probability to manage library collections. He assigned a central role to probability in librarianship, and in a report on the research for establishing the National Lending Library for Science and Technology (NLL) his administrative assistant Miss R.M. Bunn (1957, p. 284) stated that "Dr. Urquhart is beginning to regard an understanding of the use of probability mathematics in a library as a more essential requirement than a knowledge of cataloguing and classification schemes." In his Principles D. J. Urquhart (1981, p. 76) emphasized the necessity of librarians being numerate as well as literate, and he defined numeracy as requiring knowledge of not only arithmetic but also statistics. In particular, Urquhart stressed the importance of having some understanding of the Poisson distribution. He was far in advance of his field in this matter, and in his autobiography D. J. Urquhart (1990, p. 61) reports that the librarians present at his first lecture on the NLL in 1957 were incapable of understanding his explanation of the Poisson formula, being totally baffled by what "e" meant.

In his Principles D. J. Urquhart (1981, p. 30) claims that his application of the Poisson distribution to library collection 
management was the only occasion he could remember of using any of the specific knowledge he had learned in his study of physics. However, there is circumstantial evidence that Urquhart had little formal training in probability and statistics. One sign of this was his constant attribution of Bortkiewicz's analysis of the number of Prussian soldiers kicked to death by horses to Poisson himself despite every statistics textbook clearly stating that this study had been done by Bortkiewicz. Thus, D.J. Urquhart (1981) wrote in his Principles: "Poisson was studying the number of grooms kicked to death by horses in the Prussian army" (p. 76). This mistake is almost a hallmark of Urquhart's writing, making it possible to identify his authorship even when it appears that he may have been deliberately trying to conceal it. Although Urquhart never states this, my own hypothesis is that Urquhart became acquainted with the practical application of the Poisson during his war work at the Ministry of Supply. As the model of infrequent occurrences tightly grouped around a mean, the Poisson distribution is widely used in industrial quality control to determine whether a given consignment is meeting specifications, and that was Urquhart's main area of responsibility during the war. Much of Urquhart's work with the Poisson bears the mark of this industrial application being used to manage serials. Another sign of Urquhart's lack of formal training in probability is that he never went beyond the simple Poisson model despite working with compound Poisson distributions. However, he used the simple Poisson model in a way that is compatible with the compound Poisson model, achieving correct results with this simplified method, and that was all he really cared about anyway. Urquhart's main goal in utilizing the Poisson was to identify high use serials to ensure their availability through duplication and special binding procedures as well as for their more costeffective housing.

\section{The Analysis of 1956 Science Museum Library (SML) External Loans}

Urquhart's importance in the history of library and information science is that he was the first person to analyze library use scientifically and to apply a probability model to it. This importance is enhanced by where he did this analysis and the nature of the library use he analyzed. Urquhart analyzed what may be termed "supralibrary use." This is the use of materials supplied by a library to its patrons not from its own holdings but from the outside through either central document delivery or interlibrary loan. Supralibrary use is to be distinguished from intralibrary use, which is the use of materials by patrons of a library from the latter's own holdings. It was the analysis of supralibrary use that enabled Urquhart to make some unique findings about the nature of overall or aggregate library use that could not have been made in a standard study of intralibrary use. The analysis was conducted as part of the preparations for the establishment of the National Lending Library for Science and Technology (NLL), and it was a study of the loans of scientific periodicals made by the Science Museum Library (SML) in
1956 to external organizations. Bradford had developed the SML into the largest, most important scientific library in the United Kingdom, and in 1926 had started a loan service to make it a national lending library in the scientific and technical fields. This was not the first study of SML use by D. J. Urquhart (1990, p. 11), who reports in his autobiography that he had conducted what may have been the first study of periodical use during his initial tenure at the SML just prior to World War II. This study became a basis for deciding which journals should be evacuated from London in case of war. The revolutionary nature of the study of 1956 SML external loans of scientific periodicals is revealed in a report by D.J. Urquhart (1960, p. 56), in which he stated that his DSIR unit had not been able to obtain any information useful for the establishment of the NLL from library literature or practicing librarians but had to collect this information itself. He attributed this to the fact that most librarians with any intellectual training had been educated in the humanities.

The findings of the analysis of 1956 SML external loans were presented in two papers. One was a report delivered by D.J. Urquhart (1959a, pp. 287-312) to the International Conference on Scientific Information held in Washington, DC, in 1958. This conference was a successor to the 1948 Royal Society Scientific Information Conference. The other paper was jointly written by Urquhart and Bunn (1959). In his report to the Washington conference, Urquhart stated that the aim of the SML analysis was to determine the following: (1) which serials were so heavily used that they should be held by the NLL, (2) what back runs of serials should be collected, (3) which serials should be duplicated or bound in parts, and (4) which serials were so little used that one copy either at the SML or NLL should suffice. In the discussion following his paper, D.J. Urquhart (pp. 310-311) revealed his basic attitude toward research by stating that the business of measuring what scientists do should not be overdone, that crude and simple measures can be quite useful for many purposes, and that highly developed experimental techniques are often unnecessary.

In his Washington conference report D.J. Urquhart (1959a) laid the foundation of what he later came to term "Urquhart's Law." At its beginning he declared (p. 288) that the analysis of the external loans of scientific periodicals made by the SML in 1956 was probably the largest survey of the actual use of scientific serials that had ever been made. Two points were emphasized by Urquhart in his report. The first was that there had been found a positive relationship between the number of times a scientific periodical had been loaned by the SML to an external organization and the total number of holdings of this periodical as was given by the British Union Catalogue of Periodicals (BUCOP) for the main libraries of the United Kingdom. D.J. Urquhart (1959a, pp. 289-290) proved this by first averaging the number of BUCOP holdings of the 10 journals most heavily borrowed from the SML by the external organizations. The mean number of loans for these titles was 232.5. He then averaged the BUCOP holdings for samples of 10 titles externally loaned respectively 20,2 , and 0 times. 
TABLE 1. Relationship of number of 1956 Science Museum Library (SML) external loans to number of holdings listed in the British Union Catalogue of Periodicals (BUCOP).

\begin{tabular}{lc}
\hline Loan class & $\begin{array}{c}\text { Mean no. BUCOP } \\
\text { holdings }\end{array}$ \\
\hline 10 titles most Frequently loaned & 57 \\
$\quad$ (mean no. loans = 232.5) & \\
Sample of 10 titles loaned 20 times & 22.4 \\
Sample of 10 titles loaned 2 times & 4.5 \\
Sample of 10 titles loaned 0 times & 2.3 \\
\hline
\end{tabular}

Note. Adapted from "Use of Scientific Periodicals," by D.J. Urquhart, Proceedings of the International Conference on Scientific Information, Washington, D.C., November 16-21, 1958 (Washington, D.C.: National Academy of Sciences, National Research Council, 1959), Vol. 1, p. 291, Table VI.

Urquhart's results are reproduced in Table 1. This table shows that the mean number of BUCOP holdings skews rapidly downward in direct relationship to the mean number of external loans from 57 holdings for 232.5 loans, to 22.4 holdings for 20 external loans, to 4.5 holdings for 2 external loans, to 2.3 holdings for 0 loans. Urquhart regarded this finding as most interesting, because external organizations would naturally borrow from the SML scientific literature, which they themselves not only did not hold but also could not obtain from some more accessible collection. Thus, the demand on the SML was generally only a residual demand. Urquhart concluded from this finding that the external loans of a given scientific periodical from the SML was a rough indicator of the total use value of this periodical in the United Kingdom. In other words, the supralibrary use of scientific journals is very similar to their intralibrary use, and both supralibrary and intralibrary use are parts of overall or aggregate library use.

The second point, which D. J. Urquhart (1959a) emphasized in his Washington conference report, was that only a small proportion of the serials satisfied the bulk of the external demand. Urquhart stated that extensive use of scientific literature is confined to a small fraction of the total output, so that even in a library which was designed to deal with residual demand from other libraries, about 1,250 serials—or less than $10 \%$ of the scientific periodical holdings of the SML with the inclusion of noncurrent titles-was sufficient to meet $80 \%$ of the demand for serial literature. One reason for this result was that of the 9,120 current scientific titles at the SML 4,821, or 52.9\%, had not been borrowed at all in 1956 . What is of particular interest in the results reported by Urquhart is that the journals most heavily borrowed in 1956 from the SML by external organizations consisted of prestigious titles to a great extent. Thus, among the 10 most heavily borrowed journals were the Proceedings of the Royal Society of London (Series A), Science, and the Journal of the Chemical Society. Urquhart concluded his report by asking the question about whether the small use of such a large number of scientific serials was because of the low value of, or to ignorance about, their contents.
Using data presented by D. J. Urquhart (1959a) in his Washington conference report and by Urquhart and Bunn (1959a), it has proven possible to reconstruct a fair estimate of the distribution of scientific journals by 1956 SML scientific loans. The key to making this estimate is the following summary of the distribution presented by Urquhart and Bunn (1959):

In general it seems that a small percentage of the current serial titles account for a large percentage of the use of all serials. In the Science Museum in 1956 about 350 titles accounted for 50 per cent. of the total use of serials, and about 1200 titles for 80 percent. of the total use. This, despite the fact that in 1956 the Science Museum Library contained 9120 current serials, and possibly an equal number of dead ones. (p. 21)

From this it is possible to deduce that in 1956 the SML had a total of approximately 18,000 current and noncurrent serials. Because D. J. Urquhart (1959a, p. 289) reported that 5,632 titles had been loaned, this leaves an estimated zero class of 12,368 titles, or $68.7 \%$, of the collection. An estimate of the full distribution of journals by 1956 SML external loan classes is given in Table 2, and a graphic representation of this distribution is given by the bar chart presented in Figure 1. The key features of this distribution, which are revealed by this table and chart, are the heavy concentration of journals in low-frequency classes of zero to nine loans and the long, positive skew of titles to the right. Table 3 demonstrates two methods of aggregating Urquhart's data that are suggested by the above quote from Urquhart and Bunn (1959). The first method aggregates the data into two loan classes: low (0-9) and high (10-382). Here it is seen that the 1,251 titles in the high class representing $6.95 \%$ of the SML collection accounted for an estimated $79.11 \%$ of the external loans. The second method breaks out a super high loan class of 40 to 382 loans. This super high class

TABLE 2. Observed distribution of titles and 1956 Science Museum Library (SML) external loans over loan classes.

\begin{tabular}{lrrrr}
\hline Loan class & $\begin{array}{c}\text { Observed } \\
\text { no. titles } \\
\text { per class }\end{array}$ & $\begin{array}{c}\text { Observed } \\
\% \text { titles } \\
\text { per class }\end{array}$ & $\begin{array}{c}\text { Observed } \\
\text { no. loans } \\
\text { per class }\end{array}$ & $\begin{array}{c}\text { Observed } \\
\% \text { loans } \\
\text { per class }\end{array}$ \\
\hline 0 & 12,368 & $68.7 \%$ & 0 & $0.0 \%$ \\
1 & 2,190 & $12.2 \%$ & 2,190 & $4.1 \%$ \\
2 & 791 & $4.4 \%$ & 1,582 & $3.0 \%$ \\
3 & 403 & $2.2 \%$ & 1,209 & $2.3 \%$ \\
4 & 283 & $1.6 \%$ & 1,132 & $2.1 \%$ \\
5 to 9 & 714 & $4.0 \%$ & 5,002 & $9.4 \%$ \\
10 to 19 & 541 & $3.0 \%$ & 7,732 & $14.5 \%$ \\
20 to 29 & 229 & $1.3 \%$ & 5,284 & $9.9 \%$ \\
30 to 39 & 136 & $0.8 \%$ & 4,446 & $8.4 \%$ \\
40 to 49 & 92 & $0.5 \%$ & 3,773 & $7.1 \%$ \\
50 to 99 & 193 & $1.1 \%$ & 12,386 & $23.3 \%$ \\
100 to 382 & 60 & $0.3 \%$ & 8,480 & $15.9 \%$ \\
Sum & 18,000 & $100.0 \%$ & 53,216 & $100.0 \%$ \\
\hline
\end{tabular}

Mean $=2.96$

Variance $=134.29$ 


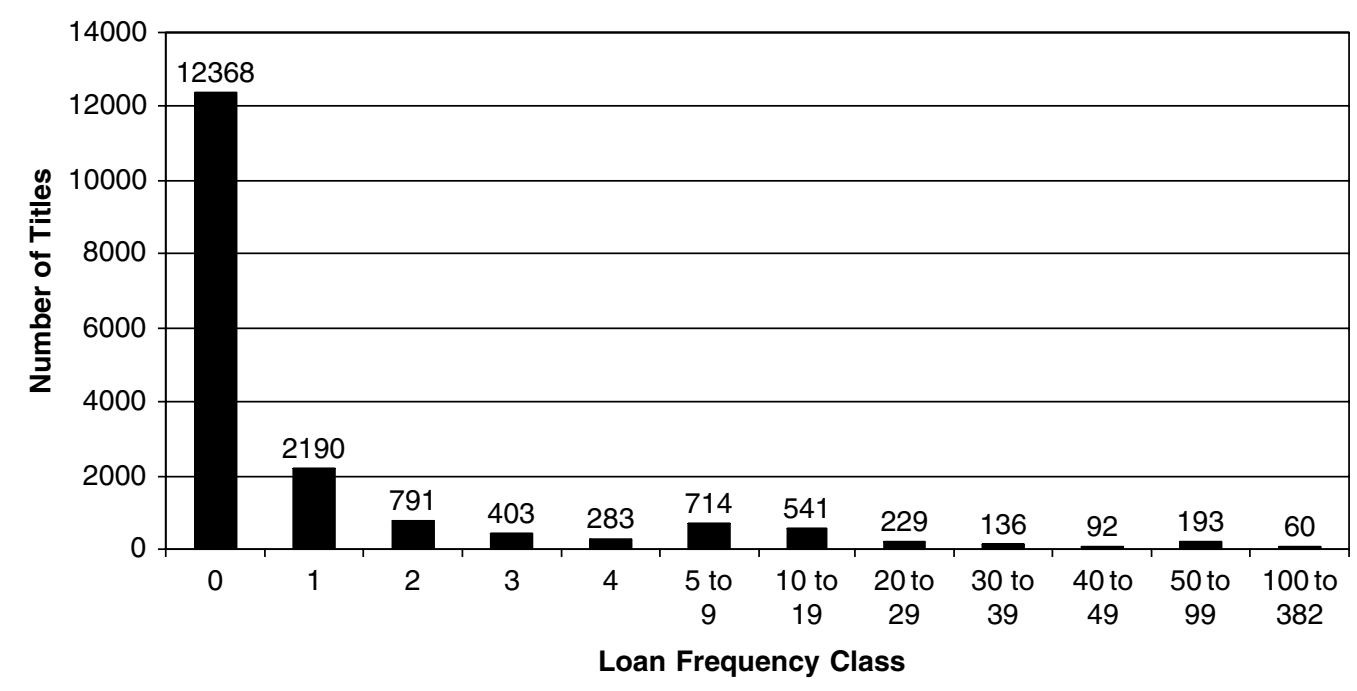

FIG. 1. Frequency distribution of scientific journal titles by 1956 Science Museum Library (SML) external loan classes.

TABLE 3. Two methods of aggregating 1956 Science Museum Library (SML) external loan classes.

\begin{tabular}{|c|c|c|c|c|}
\hline \multicolumn{5}{|c|}{ 1. Two classes } \\
\hline Loan class & $\begin{array}{l}\text { No. titles in } \\
\text { class }\end{array}$ & $\begin{array}{l}\text { Loans per } \\
\text { class }\end{array}$ & $\begin{array}{c}\% \text { titles per } \\
\text { class }\end{array}$ & $\begin{array}{l}\% \text { loans } \\
\text { per class }\end{array}$ \\
\hline Low (0 to 9$)$ & 16,749 & 11,115 & $93.05 \%$ & $20.89 \%$ \\
\hline High (10 to 382 ) & 1,251 & 42,101 & $6.95 \%$ & $79.11 \%$ \\
\hline Sum & 18,000 & 53,216 & $100.00 \%$ & $100.00 \%$ \\
\hline \multicolumn{5}{|c|}{ 2. Three classes } \\
\hline Loan class & $\begin{array}{l}\text { No. titles in } \\
\text { class }\end{array}$ & $\begin{array}{l}\text { Loans per } \\
\text { class }\end{array}$ & $\begin{array}{c}\% \text { titles per } \\
\text { class }\end{array}$ & $\begin{array}{l}\% \text { loans } \\
\text { per class }\end{array}$ \\
\hline Low (0 to 9$)$ & 16,749 & 11,115 & $93.05 \%$ & $20.89 \%$ \\
\hline High (10 to 39$)$ & 906 & 17,462 & $5.03 \%$ & $32.81 \%$ \\
\hline $\begin{array}{l}\text { Super high } \\
\quad \text { (40 to } 382)\end{array}$ & 345 & 24,638 & $1.92 \%$ & $46.30 \%$ \\
\hline Sum & 18,000 & 53,216 & $100.00 \%$ & $100.00 \%$ \\
\hline
\end{tabular}

contains merely 345 titles, or $1.92 \%$, of collection but accounts for an estimated $46.30 \%$ of the loans. These figures closely match those reported by D. J. Urquhart (1959a) and Urquhart and Bunn (1959).

Both D. J. Urquhart (1959a, p. 291) and Urquhart and Bunn (1959, p. 21) posited the simple Poisson as the correct model for the distribution of journals by 1956 SML external loans. However, neither of these papers actually tested this hypothesis. Instead there were given hypothetical distributions that would result over a given set of titles on the assumption of the Poisson at certain lambdas. In each case the lambdas were set low enough -0.5 loan per year in the first paper, and two loans per year in the second-to produce a heavy concentration of titles in the loan classes from zero to two to simulate superficially the distribution actually observed. However, two tests of the data demonstrated that this hypothesis was wrong. First, the mean and variance of the observed distribution were estimated to be respectively 2.96 and 134.29. Needless to say, Fisher's index of dispersion test for the Poisson distribution found that the estimated variance was significantly higher than the estimated mean. What this suggests is that Urquhart was dealing not with a simple but a compound Poisson distribution that was highly skewed as a consequence of both Lexian and Pearsonian factors. In other words, the 1956 SML scientific periodical set was not a homogeneous set governed by a single low probability but a Lexian mixture of subject subsets with different underlying probabilities, and within each subject subset the probabilities of the individual titles being borrowed were highly skewed in accordance with Pearsonian principles. Moreover, the high ratio of variance to the mean also indicates that the borrowings were not independent but that the probabilities of a given title of being borrowed were being altered by the very fact of being borrowed or not being borrowed.

The second method of verifying the hypothesis of the simple Poisson was Pearson's chi-squared goodness of fit test. To do this, a hypothetical simple Poisson distribution of the titles over the 1956 SML external loan classes was constructed by using 2.96 as the estimated lambda, and the observed distribution was then compared to this theoretical distribution. The results are shown above in Table 4, and the chief differences between the observed and theoretical distributions are mainly three. First, the number of titles observed in the zero class is far higher-12,368 versus 936than that predicted by the simple Poisson. Second, the number of titles observed in loan classes 2 and 3 around the mean of 2.96 is far less than that predicted by the simple Poisson. And, third, the number of titles observed in the high loan class running from 10 to 382 is far higher-1,251 versus 18 - than that that predicted by the simple Poisson. As a matter of fact, if the observed distribution had matched the simple Poisson, there would have been zero titles in the super high loan class of 40 to 382 instead of the observed 345 titles, which accounted for $46.30 \%$ of the 1956 SML external loans. Therefore, one of Urquhart's major empirical 
TABLE 4. Chi-squared goodness-of-fit test of the observed distribution of journal titles over 1956 Science Museum Library (SML) external loan classes to the distribution of titles predicted by the simple Poisson.

\begin{tabular}{lrrr}
\hline Loan class & $\begin{array}{r}\text { No. titles } \\
\text { observed }\end{array}$ & $\begin{array}{r}\text { No. titles } \\
\text { predicted }\end{array}$ & Chi-squared \\
\hline 0 & 12,368 & 936 & $139,615.83$ \\
1 & 2,190 & 2,767 & 120.48 \\
2 & 791 & 4,091 & $2,661.80$ \\
3 & 403 & 4,031 & $3,265.75$ \\
4 & 283 & 2,980 & $2,440.58$ \\
5 to 9 & 714 & 3,177 & $85,349.30$ \\
10 to 382 & 1,251 & 18 & $235,362.90$ \\
Sum & 18,000 & 18,000 & \\
\hline
\end{tabular}

$1=5$

Degrees of freedom $=$ no. classes-1-no. fitted parameters $=7-1-$

At 5 degrees of freedom the probability of a chi-squared value above 16.75 is 0.005 .

findings was a probabilistic impossibility according to his own theoretical model. The shift of observed frequencies from the mean to the two extremes is technically known as "overdispersion," and it is easy to see the Matthew Effect in this, as the larger number of titles in the zero loan class was certainly a function of the larger number of titles in the highloan class, which had a loan level that ranged far above that possible under the conditions of the Poisson. To demonstrate visually the differences of the observed distribution from the simple Poisson, there was constructed a graph of the latter distribution that is shown in Figure 2. Comparison of the graph in Figure 2 with the bar chart in Figure 1 shows that the simple Poisson is clumped tightly around a very low mean signifying a very low underlying probability with no long, positive skew to the right.
In a series of lectures delivered in 1962 at the Brookhaven National Laboratory Price (1963, pp. 74-75) discussed Urquhart's report to the 1958 scientific information conference in Washington, referring to it as "a now classical paper by Urquhart." These lectures were part of a series dedicated to the societal aspects of science, and Price focused on the social significance of Urquhart's findings. He noted that the distribution of journals by the number of loans in 1956 from the SML to external organizations was equivalent to the distribution of scientists by productivity. Price described it as "the same Pareto curve as in the distributions of incomes or sizes of cities, apparently for much the same reasons."

\section{Validation and Rejection in the United States: \\ The National Library of Medicine (NLM) and University of Chicago Studies}

The empirical findings of the analysis of the 1956 SML external loans were replicated by a study done in the United States shortly after Urquhart delivered his paper to the Washington conference. This study was an analysis of the 77,698 requests made to National Library of Medicine (NLM) by some 1,780 domestic and foreign libraries in 1959. Its findings were reported by Kurth (1962). Thus, like Urquhart's SML study, the NLM project was an analysis of the supralibrary use of scientific journals. The NLM study also found a high concentration of interlibrary loans on a relatively small proportion of the titles. This, too, was a function of a huge zero class of some $88 \%$, because only 4,347 titles out of the approximately 37,000 in the NLM satisfied $100 \%$ of the requests. Moreover, of the 4,347 titles that were used, 1,235, or $28.4 \%$, were loaned only once. Kurth (1962, p. 21) divided the titles that were loaned into classes by level of use, and these

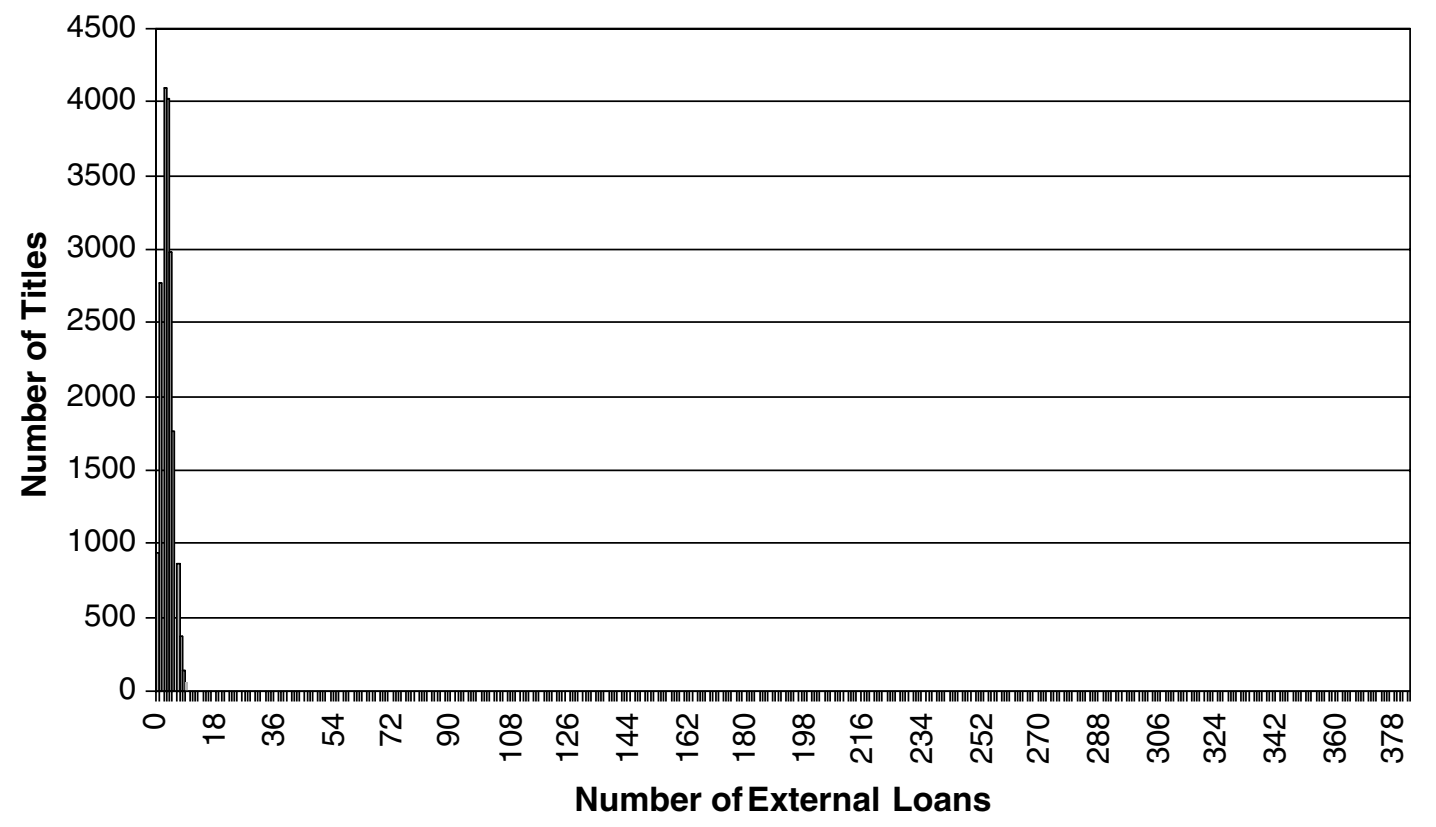

FIG. 2. Simple Poisson model of the distribution of scientific journals by number of 1956 Science Museum Library (SML) external loans. 
were summarized as follows: heavy use-161 titles (3.70\%), 30,203 loans (38.87\%); moderate use $-1,185$ titles $(27.26 \%)$, 38,512 loans (49.56\%); and low use-3,001 titles (69.03\%), 8,983 loans (11.56\%). A list of the 300 titles most heavily borrowed from the NLM was published by Kurth (1962, pp. 32-38) in descending rank order of use, and here, too, there was evident a concentration of interlibrary loan use on prestigious titles. Thus, among the 15 top titles were such titles as Lancet, British Medical Journal, Journal of the American Medical Association, New England Journal of Medicine, Science, and Nature. In accordance with Urquhart's theory, 4 of the top 10 titles-Lancet, British Medical Journal, Journal of the American Medical Association, and Journal of Clinical Investigation-were also among those found highest in intralibrary use by studies done at Yale University, the Mayo Clinic, and the College of Physicians Library in Philadelphia. Kurth (p. 47) also reported that a great many interlibrary loan requests concerned relatively common titles. The NLM study occurred while Urquhart was in the midst of setting up the NLL, and he paid close attention. D.J. Urquhart (1963) described the NLM list of the 300 most heavily used titles as being helpful to special libraries in deciding which titles to collect.

Although the results of the analysis of the SML's external loans in 1956 were empirically corroborated by the NLM study, Urquhart's hypothesis of the Poisson as the model of library use was tested and rejected in a study led by a member of the audience for his paper at the 1958 scientific information conference in Washington. This person was Herman J. Fussler, who shortly after the conference directed a relegation study at the University of Chicago. In his conference paper D.J. Urquhart (1959a, p. 291) did not specify the Poisson by name but only used it to model what could be expected under the assumption of the random distribution of demand. Fussler appeared to agree with this assumption by stating during the discussion following Urquhart's paper that studies thus far had not advanced a satisfactory explanation of the apparent unsystematic use of available sources and services for scientific information (Urquhart, 1959a, p. 310). The University of Chicago study appeared under the authorship of Herman J. Fussler and Julian L. Simon (1969). Fussler was only responsible for the specification of the general problem analyzed by the project, while Simon was responsible for working out most of the procedures, devising several lines of investigation and the initial interpretation of the data. Simon obtained his doctorate in 1961 from the University of Chicago Graduate School of Business on the basis of the project with a dissertation on the economics of book storage plans. It marked the beginning of his career as a famous-or infamous, if you are a Malthusian environmentalist-economic and social statistician. The project had the statistical support of a number of University of Chicago faculty, including the well-known statistician, William E. Kruskal. (As a historical aside, it is interesting to note that Fussler was not the only American present at Urquhart's Washington conference talk later to play an influential role in the development of information science in the United
States. The record shows that Eugene Garfield also attended Urquhart's session.)

The University of Chicago study differed from Urquhart's SML analysis in a number of key respects. First, it was a study of intralibrary and not supralibrary use. Second, it analyzed both monograph and journal use and not just journal use. Third — and most important statistically—it did not approach the problem globally as did Urquhart but only on the basis of subject sets defined by conventional library classification systems. This has the tendency to reduce the Lexian causation of skewed distributions by making the sets more homogeneous in terms of possible subject subsets with wildly different underlying probabilities. The project was based on a random model of book use, by which it was assumed that at any given moment each book in the library had a random probability of being used. This probability was estimated by grouping books together on the basis of common characteristics and then observing the use of this group. Use was hypothesized to be independent in that the use of a book depended only on the underlying probability, which could change from year to year, and not on whether it had been used in a previous period. The Chicago project specifically tested to see whether book use is contagious-i.e., whether the use of a book in one year raises its probability of being used in the next year-and found that the assumption of independence of use from one time period to another seemed to be supported by the data. However, it was admitted that the contagion test was imperfect because of the overall decrease in the use of books over time-or obsolescence-as well as by changes in the university population and book use. It will be seen later that such a conclusion may not have been tenable.

Monograph use in two subject sets-Economics and Teutonic Languages \& Literatures-during the period 1954-1958 was used by the Chicago project (Fussler \& Simon, 1969, pp. 14-34) to test the efficacy of a number of variables as predictors of library use. It was found that the best predictor of the future use of a title was its past use-a result that logically appears to have proven the operation of contagion. Such a conclusion appears even more justified by the fact that when the monograph use in both subject sets was fitted to the Poisson (pp. 187-189), the observed distributions did not resemble the Poisson by having a much higher variance caused by more observations than predicted at both the zero and the higher use points. The lack of fit of the Poisson to the distribution of monographic use was demonstrated with two graphs that are reproduced in Figure 3. In these graphs the observed distributions are depicted with bars, and the theoretical Poisson distributions at the given lambdas are designated with points. Analysis of these graphs reveals that the observed distributions of Chicago monographic use in Economics and Teutonic Languages \& Literatures manifest the same signs of overdispersion that are evident in the bar chart of SML external loans in Figure 1. Here are the same high concentration below the mean, the same reduction below the expected at the mean, and the same long tail to the right. These are the sure signs of 

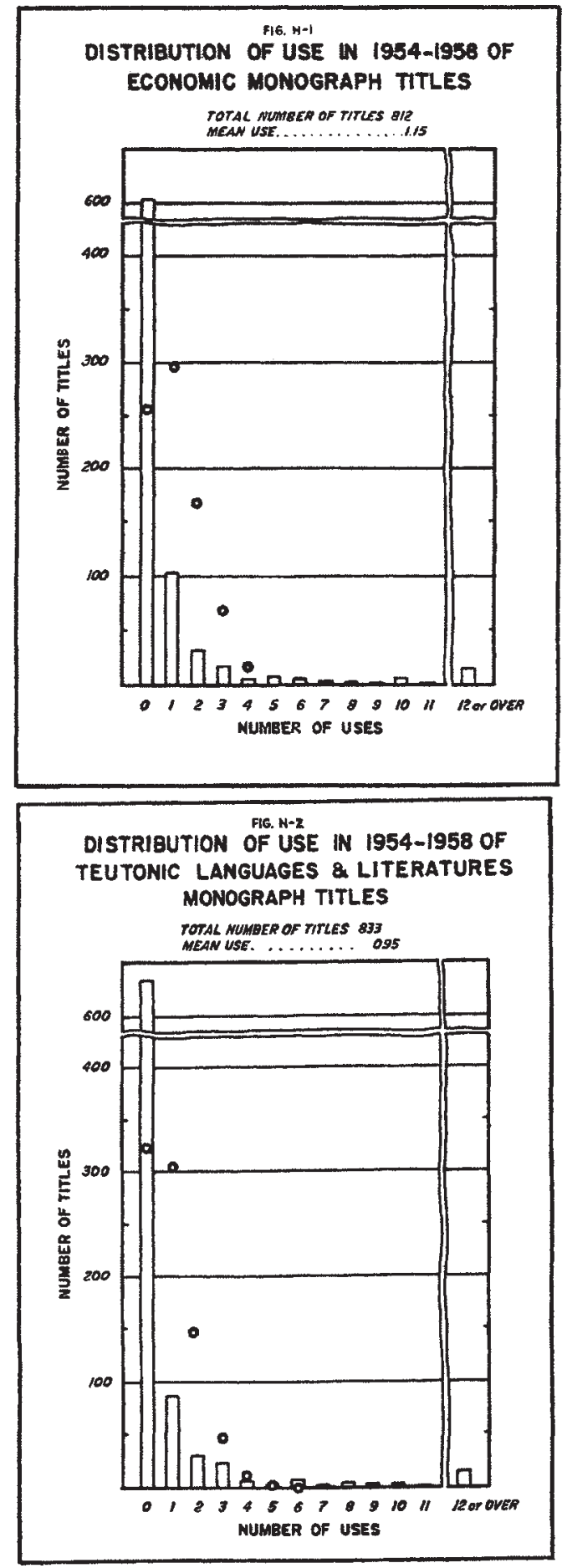

FIG. 3. University of Chicago study graphic demonstrations of simple Poisson model's failure to fit monographic use in two subject classes.

Note: From Patterns in the Use of Books in Large Research Libraries, by H.H. Fussler \& J.L. Simon (Chicago: University of Chicago Press, 1969), pp. $188-189$.

the operation of a compound Poisson distribution of the negative binomial type resulting from inhomogeneity and contagion. It can be theorized that the inhomogeneity was more Pearsonian than Lexian as a result of the set definition by subject. The assumption of contagion seems even more justified by the finding of the Chicago project (pp. 68-92, 145) that the decline in monograph use over time because of obsolescence was less than previously assumed and that this use continued to decrease indefinitely with the age of the title at a percentage rate that itself tended to decrease over time.

However, although disproving Urquhart's hypothesis of the simple Poisson as the model for overall library use, the Chicago project's findings lent support to his deduction that supralibrary use is an indicator of intralibrary use. This was done by the Chicago project (pp. 53-67 and 146) in a comparison of book use at the University of Chicago to book use at Northwestern University, Yale University, and the University of California at Berkeley. An examination of the relative amount of use of the same books at the different libraries indicated that there is a considerable similarity in the reading interests of scholars at different institutions and that for those titles held in common predictions about future use at one institution would be quite accurate in predicting future use of the same books at other institutions. From this finding it is possible to hypothesize that supralibrary use and intralibrary use are both parts of aggregate library use and that libraries will tend to lend each other materials needed and therefore held by many libraries.

\section{Urquhart, Probability, and Collection Management}

Urquhart's use of probability to manage scientific journal collections was based on the assumption that the past use of a serial could be used to predict its future. A theoretical basis for this assumption was established by the Chicago project (Fussler \& Simon, 1969, pp. 93-106, 147), which concluded that the most important characteristic of serials is their nature as families of volumes whose use patterns are related to each other. This causes the use of volumes within the same serial to be closer to each other than to the amount of use of volumes chosen randomly from other serials, making it possible to employ the use of past volumes of a serial to predict the use of future volumes of the same serial. In this it is also possible to hypothesize the effect of contagion.

The assumption of the ability to predict the future use of serials from past use was implicit in the initial planning for the NLL. D. J. Urquhart (1957, p. 23) noted that serial publications would form the main part of the collections of the intended NLL, stating, "For serials it is possible to predict roughly the demand for future issues from the demand for existing issues. ..." Bunn (1962) reported that this assumption was one of five factors that were explicitly taken into consideration in developing a periodical binding policy during the planning of the NLL. She stated this assumption: "It is possible to predict the future demand on a periodical title if the previous demand is known" (p. 20). As noted earlier, the University of Chicago study tested and validated this assumption. However, Urquhart carried the matter one step further by using probability in implementing this assumption in the management of scientific journal collections. One logical consequence of this assumption is that there is a certain stability in journal use and therefore in the rank order of 
TABLE 5. Ninety-five percent confidence limits for the expectation of library use as a Poisson variable.

\begin{tabular}{|c|c|c|c|}
\hline \multirow[b]{2}{*}{ Observed use } & \multicolumn{2}{|c|}{ True mean use likely to be within } & \multirow{2}{*}{$\begin{array}{l}\text { Range from } \\
\text { minimum to } \\
\text { maximum }\end{array}$} \\
\hline & Minimum & Maximum & \\
\hline 0 & 0.000 & 3.69 & 3.69 \\
\hline 3 & 0.619 & 8.77 & 8.15 \\
\hline 8 & 3.45 & 15.76 & 12.31 \\
\hline 15 & 8.40 & 24.74 & 16.34 \\
\hline 24 & 15.38 & 35.71 & 20.33 \\
\hline 35 & 24.38 & 48.68 & 24.30 \\
\hline 50 & 37.11 & 65.92 & 28.81 \\
\hline
\end{tabular}

journals by use over time. What Urquhart did was to use the Poisson distribution to determine the limits within which this use would fluctuate and therefore define the amount of stability in this rank order. D. J. Urquhart (1981, pp. 76-78) gives a clear explication of his method in Appendix A of his Principles, "A Note on Statistics for Librarians." Explained in probabilistic terms, he first partitioned the journal collection-best represented by the compound Poisson distribution-into its individual components or titles, which then could be modeled by the simple Poisson distribution. To accomplish this, each title could be assumed to be a set of volumes with their own lambda or mean rate of use over some period of time, around which observed use would fluctuate within certain statistically determined confidence limits. In the appendix Urquhart presented a table, which I have determined that he based on Table 40, "Confidence limits for the expectation of a Poisson variable" in Pearson and Hartley (1966, p. 227). I have replicated Urquhart's table in Table 5 here, making some modifications intended to elucidate certain key findings made by Urquhart. This table should be read in the following way: If during an observation period a scientific journal was used eight times, then there is a $95 \%$ probability that the true lambda or mean rate of use for the period was between 3.45 and 15.76. Of great importance in the table is the fact that the range between the minimum and maximum confidence limits shrinks in proportion to the diminishing of the posited mean. One factor leading to the Poisson distribution is the loss of variance as the mean shrinks, and in this lies the mechanism leading to the validity of Bortkiewicz's Law of Small Numbers.

In his autobiography D.J. Urquhart (1990, pp. 222-223) employs a technique for estimating the confidence limits around the Poisson lambda that can be done without resorting to the above table. This technique is based on the property of the Poisson distribution that lambda equals both the mean and the variance. Therefore, the standard deviation can be easily calculated by taking the square root of the lambda or mean. In his autobiography Urquhart postulates a given periodical as a group of volumes having a lambda or mean rate of use over some period of time, and he calculates the confidence interval of this lambda with a formula that makes its range from 2 standard deviations below the mean to 2 standard deviations above the mean. I have tested this method for lambdas of 3, 15, and 50, obtaining the following results: confidence interval for 3 is 0.00 (or -0.46 in actuality)-6.46; confidence interval for 15 is 7.25-22.75; and confidence interval for 50 is $35.86-64.14$. Although technically the standard deviation describes the dispersion around the mean and not the dispersion of the mean, this method yields estimates fairly close to the equivalent $95 \%$ confidence intervals in the Table 5 and is probably good enough for library purposes. It should be noticed that this technique is of no help in estimating the upper confidence limit of zero, and knowledge of this may be crucial in the management of library collections and other information databases.

The significance of the fluctuation of the Poisson lambda within confidence limits can be appreciated by analyzing this phenomenon in terms of the distribution of loans made by the SML to external organizations in 1956. To demonstrate this, there will be used the two-class partition of the SML's journal collection into a low-loan class (0 to 9 external loans) and a high-loan class (10 to 382 external loans) in Table 3. A glance at the confidence limits set forth in Table 5 shows that there could be considerable instability around the border of 10 external loans with titles shifting between the high-loan and low-loan classes from one sampling period to the next. Thus, titles with 15 observed external loans could easily be in the low-loan class on the next sampling, whereas titles with eight observed external loans could just as easily be in the high-loan class on the next sampling. In his Principles, D.J. Urquhart (1981, p. 77) pointed out the difficulty this caused for libraries in making decisions on removing lowuse titles from the main collection, noting that an observed use of three times in a year-considered high in many academic libraries - actually meant that this use could fluctuate from one to nine times. However, returning to the $1956 \mathrm{SML}$ distribution, the further one moves in either direction from the borderline of 10 external loans, the more stable becomes the composition of the high-loan and low-loan classes. Thus, there was a very small chance of a title with an observed borrowing of 24 falling below 10 into the low-loan class, and there was a very low probability of a title with an observed borrowing of 3 rising to 10 or higher to be in the high-loan class. D. J. Urquhart (1959a) was well aware of this principle at the time he gave his report to the 1958 scientific information conference. Thus, he stated (p. 291) in this report, the fact that of the 9,120 current titles held by the SML 4,821 were not used during 1956 indicated not that SML was holding 4,821 titles that would never be loaned but only that the demand for these titles was very low. Table 5 indicates that in another year there would be a good probability that the number of their external loans use could be as high as four.

In a progress report to the international library community on setting up the NLL D. J. Urquhart (1959b) summed up the 1956 SML analysis as revealing that the main problem of a national loan service was to cater to the heavy demand for a relatively small number of serials and the small demand for a large number of serials. Bunn (1958, p. 256) supplied the numbers by reporting that the SML study had found that $80 \%$ of the demand was for serials and that $80 \%$ 
of this demand was for about 1,000 particular serials. She dismissed the rest of the serials by stating that one copy held in the NLL would be sufficient not only to meet total United Kingdom demand but also the international demand from all of Western Europe, for example. D. J. Urquhart (1957, pp. 26-27) reported that a 1951 analysis of SML loan service had revealed that three major causes of failures to satisfy loans_-"on loan," "not loanable," and "at binders"- arose mainly because the SML had as a rule only one copy of any item. To reduce the number of such failures at the new NLL, he proposed two remedies: (1) the acquisition of additional copies of items in frequent demand and (2) altering the traditional way libraries bound periodicals.

Concerning the first remedy, D. J. Urquhart (1981, pp. 77-78) explained in his Principles his method for deciding which journals required multiple copies. He based this decision on what he termed the concept of "shelf availability." For example, if in a time interval equal to 10 loan periods, a part was used on average four times, the shelf availability would be 0.6 , or $6 / 10$, with one copy. Adding an extra copy would increase the shelf availability to 0.8 by reducing the average number of loans per copy to two. In probabilistic terms the problem could then be treated as two sets with a nonavailability of 0.2 , so that the likelihood of no copy being available was $0.2 \times 0.2$, or 0.04 . To reduce unnecessary duplication, Urquhart minimized the average number of uses by employing the lower confidence limit of the observed use as the true lambda. Thus, if the observed use of 12 parts of a serial was 50, Urquhart assumed that the true use of the 12 parts was 37.1 in accordance with Table 5, and that therefore the true average use per part was $37.1 / 12$, or 3.1. To show the low use of the majority of scientific journals and the high skew in the distribution of their use, D. J. Urquhart (1959a, p. 175) reported that it had been necessary to duplicate less than 100 serials even on the assumption of a doubling of SML use.

However, it was in the second remedy for the failures to satisfy loan demand-altering the traditional way of binding periodicals - that there was most explicitly implemented the principle of being able to predict the future use of serials from their past use and therefore the relative stability of this use across time. The new policy and its rationale were set forth by Bunn (1962). Instead of combining the separate issues of highly used serials into volumes as had been traditionally done, it was decided to bind them individually. Together with the postal advantages of such a policy, Bunn pointed out that it would increase the shelf availability of articles in highly used journals, because only an individual issue would have to be sent to a given borrower, leaving the other issues of the volume on the shelf for other borrowers. Bunn reported that just over 1,500 current periodicals were being bound in such a fashion and that these periodicals included not only the 1,200 serials found most heavily used in the 1956 SML analysis but also the 300 titles most heavily borrowed from the NML in 1959. Bunn noted that about one half of the loans made from the NLL were being satisfied by periodicals with individually bound issues even though they comprised only a small percentage of the periodical stock. These same serials also received different treatment in another way. D. J. Urquhart (1962, p. 321; 1963) reported that extensive purchases of backfiles were being made only for these same serials. Moreover, Houghton (1972, p. 71) stated that the NLL held complete runs of the 1,200 most heavily used serials in a separate storage area that also housed the receipts and dispatch bay-an arrangement that facilitated the movement of the most heavily used material.

It is thus seen that Urquhart planned and constructed the National Lending Library for Science and Technology on the basis of a relatively stable core of journals that were heavily used across time as a result of the Poisson process. This concept was challenged in a series of studies done shortly after the NLL became the British Library Lending Division (BLLD) and Maurice B. Line succeeded Urquhart as Director General in 1974. In their classic study of obsolescence Line and Sandison (1974) also postulated the simple Poisson distribution as the proper model for library use, stating that "we can consider its properties a relevant guide to what might be expected" (p. 293). However, like Urquhart, they never tested their postulate against reality but only presented some hypothetical use figures that would result if such were the case. They then emphasized that in respect to serials " $n o$ existing studies can be used to predict future usage" (p. 295). This conclusion is a logical one in the light of their postulate of the simple Poisson as the proper model for library use, for this distribution is the model of total randomness. The conclusion was apparently proven empirically by two studies of BLLD use done in 1975 and 1980. As reported by Clarke (1981), it was found that of the top 5,000 titles on both the 1975 and 1980 lists only 2,591 (52\%) were common to both lists. From these results the following deduction was made: "This inconsistency of rank lists over time sheds doubt on the continuing value of core lists of serials, which might decrease substantially in validity over a relatively short period" (p. 111).

The entire basis of Urquhart's work had been undermined, and the response came in the form of an article entitled "Has Poisson Been Kicked to Death?-a Rebuttal of the British Library Lending Division's Views on the Inconsistency of Rank Lists of Serials," ostensibly written by Urquhart's son, John A. Urquhart (1982). This stinging riposte featured the Library Statistical Fraud Squad headed by Sherlock Holmes rushing off to the BLLD to investigate the murder of one Poisson, "whose name is inextricably linked to the number of horse grooms kicked to death in the Prussian army." This conflation of Poisson's name with Bortkiewicz's work is suggestive of the historical error always made by Donald, and it makes one suspect that Donald was the real author of the piece. The issue at stake was succinctly captured in the following exchange between Holmes and Watson:

'Elementary, my dear Watson. Either they would have reported near perfect overlap between the use of titles from one survey to the next, which would have meant the end of Poisson. ...' 
'But they didn't, Holmes, they said there was only some overlap, and I quote: "It certainly seems that the consistency of rank lists over time is not very high.",

'Precisely, my dear Watson, and so they concluded that use in one survey was not a good predictor. It amounts to the same thing. In either case Poisson would have been finished off.'

'Good lord, Holmes, this is serious. If they get away with the demise of Poisson there's no knowing what intellectual crimes they may go on to commit....' (p. 97)

The article contained an interesting model comprised of a matrix of simple Poisson distributions, from which it was possible to draw the following conclusions. If one restricts oneself to a set of 3,847 titles used from 3 to 10 times in one survey, assuming that their observed use is their true lambda, then, with no change in behavior, 823 , or $21.4 \%$, could drop at random below three uses on the next survey. Moreover, with the same assumptions, the number of these titles used three times could change - also at random-from 1,253 titles in the first survey to $571 \mathrm{in}$ the next. Taking this model into account together with the sampling and other methodological errors in the studies, John—or Donald—stated that the amount of overlap was fairly close to what could be expected and that therefore the BLLD conclusion as to the value of core lists of serials was wrong. In his autobiography Donald Urquhart (1990) reiterated the main point of the article by stating that those who compare rank lists often overlook the effect of the confidence limits within which Poisson lambdas move, and therefore "have come to fallacious conclusions from the changes in rank observed in different periods" (p. 223).

\section{The University of Newcastle Study of Intralibrary Use}

Urquhart's final contribution to the transition from librarianship to library and information science came not through his own research and policies but through a research project he helped sponsor at the University of Newcastle. This project made a theoretical breakthrough in the probabilistic modeling of library use, laying the final bases for the formulation by Urquhart of his law of supralibrary use. In doing so, it provided the proper perspective from which to approach the question of the stability of journal use across time. The research project, which lasted from 1973 to 1975, was an analysis of the use of materials at the University of Newcastle library. It was begun by Colin Taylor, but on Taylor's departure at the end of 1973 to take a position at the University of Western Australia, the project was taken over by Urquhart's son and daughter-in-law, John A. Urquhart and Norma C. Urquhart (1976), under whose names the project reports were published. John assumed responsibility for the project, whereas Norma did the evaluation and analysis of the data that had been collected. Like the Chicago project, the Newcastle project was done for the purpose of relegation and stock control. Despite their age, these analyses still remain among the best relegation studies ever done. The goals of the Newcastle project were established at a meeting at the NLL under the chairmanship of Donald Urquhart in January 1972. At this meeting papers by Donald and Line outlined two major areas for stock control investigations within libraries: (1) acquisitions policies in relationship to what not to acquire but to obtain through interlibrary loan and (2) retention policy in respect to what to discard or relegate from existing stock because of lack of space or other considerations.

The Newcastle project is notable for two things. One is that it was the first study to suggest the negative binomial as the correct model for overall library use. This was done by the Urquharts during their consideration of the proper methods that should be employed in the relegation of monographs. In their consideration of this problem they started from the work of Richard W. Trueswell. During the 1960s, Trueswell, a professor of industrial engineering, replicated in studies of intralibrary use at a number of libraries in the United States what Donald had first found in his 1956 SML study of supralibrary use - that the distribution of library use is highly skewed with the use concentrating on a relatively few of the items held by a library. On this basis Trueswell formulated his famous $80 / 20$ Rule, by which $80 \%$ of the use is satisfied by $20 \%$ of the collection. In his writings Trueswell generally modeled his rule with mathematical curves. Trueswell's 80/20 Rule is an empirical law derived off observations of a single phenomenon without any general applicability for scientific inference. Urquhart and Urquhart (1976) noted this aspect of Trueswell's law, writing:

It is regrettable that hitherto no explanation has been offered for the nature of the curves produced by Trueswell. Indeed, the descriptive curves have been presented as selfexplanatory. The curve is the proof. (p. 22)

Urquhart and Urquhart (1976, pp. 22-24, 39-45) then proceeded to rectify this situation. To do this, they first constructed a use curve of the type plotted by Trueswell on the basis of the simple Poisson model of overall library use. This is the model that was advanced by Donald, used, tested, and rejected by the Chicago project, as well as postulated by Line and Sandison. Urquhart and Urquhart based their model on a hypothetical library, where each book has an equal probability of 0.01 of being borrowed in any one fortnight, pointing out that with such a model $40 \%$ of the stock sample would account for $40 \%$ of total circulation. They compared the results of this model to Trueswell's 80/20 Rule and actual stock sample curves, where $40 \%$ of the stock accounted for $80 \%$ of the use, finding Truewell's rule a closer fit to reality. Urquhart and Urquhart then plotted use curves on the basis of a rudimentary compound Poisson model of a library, where $10 \%$ of the books have a 0.1 probability of being borrowed in a fortnight and $90 \%$ of the books have a 0.01 probability of being borrowed in a fortnight. They found these curves remarkably similar to some of Trueswell's curves but with $90 \%$ of the stock still exhibiting low random use. As a result of this experiment, Urquhart and Urquhart concluded that there are different levels of use within a library collection, and they therefore recommended 
the negative binomial distribution as the model for overall library use, because it plotted the Poisson curve associated with each level of use. Urquhart and Urquhart noted that negative binomial distributions are common throughout nature, modeling such diverse things as the aggregation of algae cells on cultured media, the distribution of herring shoals in the North Sea, or the spatial distribution of a field of cows. Urquhart and Urquhart (1976) took a random sample of monograph titles from the different subject areas and found that the use patterns of the sample followed the negative binomial distribution. Noting the Lexian bases of this distribution, they stated that these use patterns indicated "a somewhat heterogeneous collection of books made up of subcollections with different average levels of use" (p. 94).

Of greatest interest are the practical conclusions, which Urquhart and Urquhart (1976, pp. 95-96) drew for the relegation of monographs in respect to the nature of the probability distributions underlying their use. Here is most clearly seen the difference between an empirical law and a probability model. In line with the discussion here, the options for relegation were considered in terms of whether the distribution of the monograph use in a given subject area had been the negative binomial or the Poisson. To illustrate these options, Urquhart and Urquhart provided two graphic models - one of subject area A with the negative binomial pattern of monographic use, the other of subject area B, where monographic use followed the Poisson distribution. These graphic models are reproduced in Figure 4. According to Urquhart and Urquhart, if the use distribution had been the negative binomial, certain books would be consistently in minimal or zero demand, so that a cutoff point based on past use would be feasible. In terms of the negative binomial model of monographic use in subject area A, such a point could be set at two uses and below, thereby encompassing the majority of the monographs in this area. However, Urquhart and Urquhart state, if prior monographic use had fitted the Poisson distribution such as in subject area B, then no group of low-use monographs could be isolated, and the use of monographs would have been entirely random, so that relegation on the basis of past use would be no more efficient than relegation at random. In discussing the various options arising from this situation, Urquhart and Urquhart proposed not only relegating at random from Poisson areas like $\mathrm{B}$, if the use here were very low, but also isolating the low-use monographs in negative binomial areas such as A and relegating at random from among them. The combination of restricting the relegation process to those subject areas manifesting low Poisson use and the lower-frequency classes of those subject areas governed by the negative binomial would be restricting the field of observation to low-frequency classes no matter what the subject area and a practical implementation of Bortkiewicz's Law of Small Numbers. Although done in respect to monograph relegation, the justification and utilization of the compound Poisson by Urquhart and Urquhart to model library use provided a theoretical basis for Donald's centering his management of the NLL scientific journal collection around a high-use core. This is because it provided a theoretical framework for segmenting a library's holdings into low-use and high-use subsets, whose composition should be stable over time at both extremes but particularly at the lower frequencies, where shifts of the means are small in absolute terms.

The other notable feature of the Newcastle project was its analysis of the relationship of the intralibrary use of scientific journals to their supralibrary use. At the meeting at the NLL in January 1972 under the chairmanship of Donald, it was suggested that there be examined the question of whether an item was worth holding locally if little or no demand had been revealed for it in the records of the NLL, which shortly thereafter became the BLLD. As reported in Urquhart and Urquhart (1976, p. 56), it appeared particularly valuable to test the hypothesis that if a title has not been requested from the NLL for a given number of years, there would be no need to hold it locally. It also seemed desirable to identify the exceptions to any such rule. This in effect was an empirical test of one of the main conclusions drawn by Donald Urquhart (1959a) from his analysis of the 1956 external loans by the Science Museum Library that "the use of the copies of a serial in the library [SML] is a rough indication of its total use value in the United Kingdom" (p. 290). Not surprisingly, when Urquhart and Urquhart (1976, pp. 20-21, 65) took over the Newcastle project from Taylor, they did not think that their predecessor had given sufficient weight to the NLL data, so they expanded the NLL database
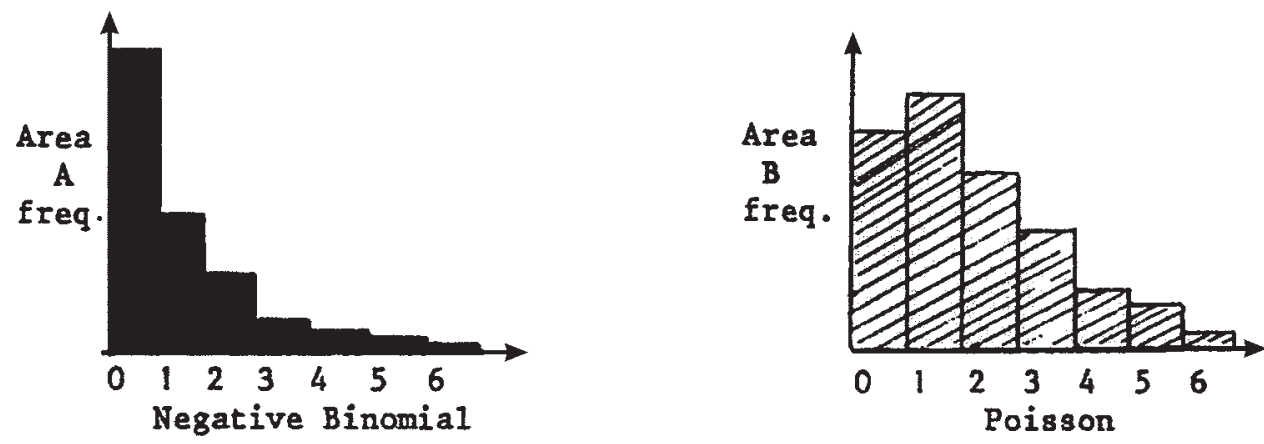

FIG. 4. Newcastle project's comparative graphic models of negative binomial and simple Poisson distributions of monographic use. Note. The horizontal $\mathrm{x}$-axis designates the number of uses for a given monograph; the vertical $\mathrm{y}$-axis indicates the number of monographs at that level of use. From Relegation and Stock Control in Libraries, by J.A. Urquhart \& N.C. Urquhart (Stocksfield, England: Oriel Press, 1976), p. 95. 
to be able to better check NLL use against Newcastle use. To assist them, Donald made available a survey of NLL use that was four years old at the time of the Newcastle project.

In approaching the problem of relegation, Urquhart and Urquhart (1976, pp. 93-94) pointed out one major advantage of serials over monographs in this matter. This was that the use of periodical material is generally more consistent within a given run, making it possible for future predictions of usefulness to the reader to be more precise. This premise had been validated by the Chicago study and was the same one on which Donald had based his work. However, they then combined this advantage with the fact that their analysis of periodical use in several subject areas had shown that the number of periodical titles used over time tends to rise and then level off at a certain ceiling, leaving a substantial zero class of periodical titles. They noted that humanities journals tended to take longer to reach this saturation point than science journals because of the greater scattering of the use of humanities materials. The Newcastle project made what was probably its most significant finding in its analysis of NLL use as a predictor of the zero class of scientific journals at the local level.

It is difficult to summarize the findings of the Newcastle project on the relationship of the use of scientific journals at the NLL to such use at the University of Newcastle library from the material published under the name of Urquhart and Urquhart (1976). This is because this volume is a rough compendium of interim and final reports as well as other items written by various authors. Moreover, there is evidence of hasty writing and inadequate proofreading resulting in numerous errors and ambiguities. However, John A. Urquhart $(1977$; 1978) published two rather cogent summaries of these findings, and these summaries are what will be used to present the results of the Newcastle analysis of the relationship of the supralibrary use of scientific journals to their intralibrary use.

In general, the Newcastle project found a strong positive association between the NLL supralibrary use of scientific journals and the Newcastle intralibrary use of such journals. John Urquhart (1978, p. 121) noted that the positive association was all the more remarkable because the NLL data was four years older than the Newcastle data. This indicates a certain stability of use across time. However, John Urquhart (1977, p. 34) pointed out that the predictive ability of the NLL data was less in a subject area like medicine, where the University of Newcastle had a strong program. To quote one set of figures given by John Urquhart (1978, p. 121), in the science category, of the 26 titles with low NLL use 17 had no current use and 9 had current use at Newcastle, whereas of the 45 titles with high NLL use 14 had no current use and 31 had current use at Newcastle. This same pattern was found in medicine. Here, of the 63 titles with low NLL use 43 titles had no current use and 20 had current use at Newcastle, and of the 70 titles with high NLL use 19 had no current use and 51 had current use at Newcastle. The NLL data performed extremely well in predicting the zero class of scientific journals at Newcastle. As stated by John Urquhart
(1977), it was better to relegate serials than monographs for the following reason: "We could ... be more confident in predicting use, or rather non-use, since we were dealing with groups of books [sic] which had relatively constant use patterns" (p. 33). He presented data showing that, with the exclusion of annual, specialist, and new journals, the NLL data had a 3\% error rate in predicting titles with zero use at the University of Newcastle library in the science category. However, in medicine the error rate was 19\%. John Urquhart (1977, p. 34) also reported that in most cases titles not held at the NLL had zero use at Newcastle. As crude as these measurements were, they did indicate that, in respect to scientific journals, there is a strong relationship of supralibrary use to intralibrary use, that libraries act not as individual units but as a system, and that Bortkiewicz's Law of Small Numbers holds not only for individual libraries but also for the library system as a whole.

\section{Urquhart's Law}

All the factors just discussed were put together in what Donald came to term "Urquhart's Law" of librarianship. In introducing his law D. J. Urquhart (1977) called it "one of the most useful laws of library science" and defined it in its more pedantic form as stating that "the inter-library loan demand for a periodical is as a rule a measure of its total use." He wrote that it should be called "Urquhart's Law," because, as far as he was aware, the existence of the law was first indicated in his report of a survey of the use of journals in the Science Museum Library in 1956. Urquhart did not regard supralibrary use as a precise measure of the total use value of a journal but declared that the measure is probably "roughly proportional." However, he then focused on the area where supralibrary use had been found by the Newcastle project to be most accurate in predicting intralibrary use because of small absolute variance-the zero- and low-use classes. Urquhart revealed what he considered to be the most significant finding of this project by stating, "A deduction from the law that if a periodical is rarely used at Boston Spa [the home of the NLL] it would be rarely used in a university library has been confirmed at Newcastle." In his Principles D. J. Urquhart (1981) gave his law the following formulation:

\footnotetext{
The fact that the heaviest inter-library demand is for periodicals which are held by a number of libraries is of major importance in designing inter-library services. To draw attention to this relationship I have called it 'Urquhart's law'. It means, for instance, that the periodicals in the Boston Spa collection which are rarely used are unlikely to be used to any appreciable extent in a British university. There may be some exceptions to this deduction and there is no precise relationship between the number of copies held by libraries, and the inter-library demand for a periodical. Nevertheless, the law is very important in considering the need for a central library collection. (p. 85)
}

The main tenets of Urquhart's Law can be summed up under the following three points: (1) The supralibrary use of 
a scientific journal is positively associated with the number of libraries holding this journal in a given library system. (2) The supralibrary use of a scientific journal is indicative of its total use value in a given library system and therefore is a predictor of its intralibrary use at the libraries within this system. (3) The libraries of a given library system have common zero- and low-use classes.

\section{Conclusion and Subsequent Validation}

That Urquhart's Law and the probabilistic breakthrough on which it is based occurred in Britain is no historical accident. Britain was one of the few countries, where the necessary scientific preconditions had not only been created but also maintained. From this perspective, the rise of information science in Britain can be interpreted partially as a further development of the Darwinian revolution and the biometric statistics stimulated by this revolution. The Urquharts served as a conduit for these statistics into librarianship, helping to convert it into library and information science. Yet, despite its crucial significance, Urquhart's Law is virtually unknown in library and information science. Its main practical application has been to serve as the operating principle behind the collection development and management policies of the National Lending Library for Science and Technology (NLL) as well as its successor organizations, the British Library Lending Division (BLLD) and the British Library Document Supply Centre (BLDSC). Outside of these institutions this law has not been widely known, understood, and accepted. Thus, in their massive textbook on collection development, Evans and Zarnofsky (2000) never mention Donald J. Urquhart and only briefly discuss the Newcastle study (p. 422).

Nevertheless, Urquhart's Law has been validated on a number of occasions. Three massive use studies done at the BLLD under Urquhart's successor, Line, in 1975 (Bower, 1976), 1980 (Clarke, 1981), and 1983 (Merry \& Palmer, 1984), found the same pattern of supralibrary use that Urquhart had found at the SML in 1956. Scales (1976) replicated Urquhart's test of the relationship of NLL use to BUCOP holdings and found that "there is a definite tendency for those journals used less frequently to be those held by the least number of libraries and vice versa" (p. 21). For their part, Line and Wood (1975) analyzed the 1975 BLLD use study from the perspective of whether central document delivery reduced the sales of journals by publishers. They found that demand at the BLLD concentrated on a relatively small number of titles, most of which were well-established journals, widely held by libraries, and with large circulations. Therefore, Line and Wood concluded that there was no relationship between BLLD use and publisher sales. Two decades later, the question of the relationship of central document delivery to journal sales was also explored by a joint study conducted by the British Library Document Supply Centre (1996) and the Canada Institute for Scientific and Technical Information. The Anglo-Canadian study came to the same conclusion as Line and Wood. It found that organizations subscribing to journals also make use of document supply services with sometimes as much as $62 \%$ of document supply demand for a particular journal emanating from organizations subscribing to it and that subscribing organizations are frequently among the heaviest users of document supply to titles, for which they have subscriptions, with one subscriber to a given journal accounting for $20 \%$ of the total document supply demand for it.

Although Urquhart regarded supralibrary use as an indicator of the total use value of a journal and therefore of its intralibrary use, he did not appear to regard it as an accurate enough indicator to be of much value to local libraries as a guide for which journals to hold. From the hypothesis set for the Newcastle project to test-that if a title has not been requested from the NLL for a given number of years, there would be no need to hold it locally - and his formulation of his law in his Principles, it is evident that Urquhart thought his law had validity for this purpose only in respect to the zero and the low-frequency classes, where Bortkiewicz's Law of Small Numbers holds sway and variance is extremely small. His successor Line (Line \& Scales, 1976; Line \& Steemson, 1977) employed the Spearman rank-order coefficient to test whether BLLD use could be used as a guide by local libraries for journal selection purposes. Given the nature of the BLLD, his initial assumption was that a list of journals ranked by BLLD use would be of little benefit to a special library but could be useful to an academic library. He conducted one test that he regarded as valid-a test of 565 titles ranked by BLLD use and that of an academic library-that yielded a significant coefficient of 0.42. Line considered this correlation as too low for the BLLD rank list to be of value as a selection tool for the library in question. Line concluded that BLLD use served only as a general indicator of the possible utility of journals at local libraries and could not be employed for the purpose of selecting individual titles.

Such conclusions make sense from the perspective of Urquhart's Law and probability theory. From the perspective of Urquhart's Law, journal use at individual libraries-both supralibrary and intralibrary - should be regarded as samples or subsets of total aggregate journal use involving all libraries. Although journals may have a certain probability of being used at the aggregate level, each library serves a different patron population in terms of subject mix. Therefore, the probabilities determining the lambdas of journals at different libraries will vary around the aggregate mean probability and not precisely match each other. The lower the aggregate lambdas of the journals, the less variance around the aggregate mean, and the more the use at one library will equal the use at another library. However, given the nature of journal use distributions, where titles are concentrated at the lower frequency levels and small changes in use can cause large changes in rank, a Spearman coefficient of 0.42 can be considered quite high. This opens the question that a BLLD use list with its estimates of aggregate lambdas could be quite helpful for at least the initial selection of individual titles at the local level, if one abandons the Spearman 
requirement of a precise match of ranks and works within broader limits. Use of the Spearman for such tests seems even more questionable in the light of the dangers pointed out by Urquhart - either John or Donald — of drawing conclusions based on rank lists in the light of the tendency of Poisson lambdas to shift within certain confidence limits from one observation period to another.

Urquhart's Law has been validated by studies conducted in the United States other than the one done at the National Library of Medicine (NLM). The most extensive of these was reported by Wood (1969). This study was conducted at the Chemical Abstracts Service (CAS) of the American Chemical Society. Unlike Urquhart's SML and the NLM studies, the CAS project analyzed not central document delivery but another form of supralibrary use-interlibrary loan-in this case, 70,686 interlibrary requests provided by 19 resource libraries evenly distributed throughout the United States. Most of these requests were made in 1967, and they originated from persons at 3,363 organizations. The CAS findings were similar to those of Urquhart in two respects. First, the distribution was the same with $1.6 \%$ of the titles accounting for $25.1 \%$ of the requests and $6.9 \%$ of the titles accounting for $50.5 \%$ of the requests. Second, there was also the same predominance of standard titles held by most libraries, with Nature and the Journal of the American Chemical Society being among the three most requested titles.

Two U.S. studies are of extreme interest when considered in relationship to each other, because they validate Uquhart's Law at both ends of the frequency distribution. The first of these was reported by Stewart (1976), and it caught the attention of D. J. Urquhart (1977) himself. Stewart described the requests filled by the Periodical Bank of the Associated Colleges of the Midwest, a consortium of ten liberal arts schools. He related the number of requests for titles in the period 1969-1972 to the number of libraries of the consortium holding the titles, showing that the bulk of the requests-6,010 out of 15,996 (37.6\%) —were for titles held by all ten member libraries. Stewart also showed that the average number of requests per title skewed rapidly downward in direct relationship to number of holdings from 71.55 for titles held by all 10 libraries to 0.01 for titles held by only one library. Stewart states that this phenomenon was totally unexpected when the Periodical Bank was established.

The validity of Urquhart's Law at the lower end of the frequency distribution was demonstrated by Price and Carey (1993) in their analysis of the results of the participation of Montana State University (MSU) in a program of the cooperative holding of scientific journals with four other universities of the Pacific Northwest. For its part, MSU Libraries purchased 86 serials with a pledge to make them readily available to the other universities. Price and Carey monitored both the MSU intralibrary use of 84 of these titles as well as their supralibrary use by the other four universities participating in the project for nine months in 1991. Of the 84 titles, 30 had no intralibrary use and - to the evident surprise of the researchers-no supralibrary use either. These results were a function of the systemic operation of
Bortkiewicz's Law of Small Numbers, and it caused Price and Carey to question the value of the cooperative holding of scientific journals.

I tested the validity of Urquhart's Law three separate times. The first occasion was when Bensman and Wilder (1998, pp. 193-199) analyzed the utilization of the UnCover document delivery system by Louisiana State University (LSU) as part of a project to explore the potential for improving the scientific and technical serials holdings of LSU Libraries. To do this, they gathered a sample of all documents delivered to LSU Libraries by UnCover during the two-year period from July 1, 1994, to June 30, 1996, from serials classed in LC subject classes Q (Science), S (Agriculture), and $\mathrm{T}$ (Technology). This sample comprised 847 serials, accounting for 2,909 document deliveries, and these serials were analyzed in terms of measures constructed on the basis of LSU faculty ratings and citation impact factor. The latter is a measure invented at the Institute for Scientific Information (ISI) to gauge the importance of the journals covered by its Science Citation Index (SCI) and its Social Sciences Citation Index (SSCI). It was found that 135 of these 847 titles (15.9\%) accounting for 250 document deliveries $(8.6 \%)$ were on current subscription at LSU Libraries despite such titles being blocked from the UnCover system. Subsequent analysis of these 135 titles revealed that $45(33.3 \%)$ were in the highest category of the faculty rating measure and $109(80.7 \%)$ were in the highest category of the citation impact factor measure. These titles were stripped from the sample, leaving 712 titles accounting for 2,659 documents. The remaining titles were then grouped into three ordinally ranked use classes: low-310 titles (43.5\%) accounting for 310 documents (11.7\%); medium-323 titles (45.4\%) accounting for 977 documents (36.7\%); and high79 titles $(11.1 \%)$ accounting for 1,372 documents $(51.6 \%)$. From the nature of these classes it is evident that the underlying distribution was similar to the one underlying 1956 SML external loans. Various tests revealed that both the LSU faculty rating and the citation impact factor measures were positively associated with UnCover document deliveries. These results demonstrate some of the factors operative at the local level in the functioning of Urquhart's Law.

The strong positive relationship of ISI citations with supralibrary library use, which was found by Bensman and Wilder at the local level, was corroborated by Bensman (2001b), who demonstrated that the same relationship exists at the central level. He did this in an analysis of the findings of Scales (1976), who used the Spearman rank-correlation method to compare NLL use in 1969 with SCI citations of the same year. Scales found that the rank order correlation between these two were too low for citations to constitute a valid guide for journal selection by libraries. However, Bensman refuted this with Scales' own data. From the perspective of Urquhart's Law, NLL use and ISI citations serve the same theoretical function as estimates of the aggregate use value of journals, and Bensman found the major fault of the Scales study in the utilization of the Spearman correlation, which is based on the precise matching of ranks. To avoid this 
requirement, Bensman employed the chi-squared test of independence after recasting Scales' use and citation data into three broad Bradford-like zones: high (top 10\%), medium (mid 15\%), and low (bottom 75\%). When this had been done, a strong positive relationship emerged between NLL use and SCI citations except in one crucial respect that demonstrated how the underlying probabilities of journals being used are affected by the subject structure of the user population. NLL use appeared oriented toward technology, whereas SCI citations were more reflective of basic science. A large proportion of the NLL demand was from industrial libraries, and the effect of this was made evident by the appearance of 13 engineering journals in the top 50 journals ranked by NLL use. In contrast, there were no such journals in the top 50 journals ranked by SCI citations. Of these 13 engineering journals, 12 appeared as outliers in the high NLL use/low SCI citation category. All this serves to prove two important points. First, the underlying probabilities of journals being used can differ from subset to subset, depending on the subject mix of the population using the subsets, and this will result in the distribution of a journal's subset probabilities around some hypothetical aggregate mean probability representing its total use value for the entire set. Second, both supralibrary use and citations can be employed for selection purposes, provided one works within broad accuracy limits appropriate for the purpose and controls for the Lexian factors underlying the skewed distributions by first classifying the journals into fairly crisp subject sets and subsets. However, it should be noted that in personal communications to this author Line (January 28, 2000; February 10, 2004) has reiterated his position that the relationship of aggregate library use to intralibrary use at the local level is too tenuous for either estimate of aggregate library use-supralibrary use or citations - to be safely employed as guides for collection management in individual libraries. Therefore, the second point may be considered moot and open to further research.

In his third test of Urquhart's Law, Bensman (2001c) used its basic principles to compare the quality of the journal coverage of three aggregators being marketed by EBSCO, Gale, and ProQuest for the Louisiana Academic Library Information Network Consortium (LALINC). Aggregators are bundles of electronic journals with their own indexing and abstracting services. The aggregators in question did not contain the more academic journals but ones of the popular type, and therefore it was thought inappropriate to use citation measures to assess the quality of their journal coverage. Instead Bensman used the quality ratings published in Magazines for Libraries (MFL) edited by Katz and Katz (2000). These ratings were considered flawed for two reasons: (1) they only represented the opinion of individual subject experts, and (2) one company was utilizing MFL as a selection tool, giving it an unfair advantage. To provide a different measure of quality, EBSCO, the main library subscription agency, supplied a list of the 1,000 titles most purchased from it by libraries, and it was decided to assess the quality of the aggregator journal coverage by the proportion of titles on this list. This measure was considered a more valid one for the following reasons. First, on the basis Urquhart's Law, number of library holdings is a general measure of intralibrary as well as supralibrary use, and the aggregators were to be used by all the libraries in LALINC. Second-and this is a major reason behind the validity of Urquhart's Lawnumber of library holdings actually represents the collective judgment of the library profession as to the importance of journals, and this was deemed a more valid measure than the individual expert opinions, on which the MFL ratings were based. Much to Bensman's surprise, the aggregator, which used Magazines for Libraries as a selection tool, scored highest on the new quality measure. This not only validated Magazine for Libraries as a selection tool but also demonstrated that the opinion of individual subject experts is an excellent gauge of the collective judgment of the profession.

Urquhart was correct-his law is "one of the most useful laws of library science." It has been seen that this law has many implications for such diverse areas as journal evaluation and selection, collection management, resource sharing, document delivery, journal sales, and so forth. Despite the work described earlier validating Urquhart's Law, much remains to be done on elucidating its ramifications. One of the most important areas is what does Urquhart's Law imply for the transition from the era of individually held paper copies, in which this law was developed, to the new era of shared electronic databases. Urquhart's Law seems to indicate two things of importance for this transition. First, access is not the primary determinant factor in journal use. Second, surpralibrary use and aggregate intralibrary use are very much the same. The logical consequence of Urquhart's Law is that there should be no change in journal use in the transition from individually held paper copies to shared electronic databases, which entail nothing more than a merger of supralibrary use with intralibrary use. But this is only a hypothesis that still needs to be tested.

\section{References}

Bensman, S.J. (2001a). Bradford's law and fuzzy sets: Statistical implications for library analyses. IFLA Journal, 27, 238-246.

Bensman, S.J. (2001b). Urquhart's and Garfield's laws: The British controversy over their validity. Journal of the American Society for Information Science and Technology, 52, 714-724.

Bensman, S.J. (2001c). Assessment of aggregator databases. Report to the LALINC Resources Development Committee, Baton Rouge, LA.

Bensman, S.J., \& Wilder, S.J. (1998). Scientific and technical serials holdings optimization in an inefficient market: A LSU Serials Redesign Project exercise. Library Resources \& Technical Services, 42, 147-242.

Bower, C.A. (1976). Patterns of use of the serial literature at the BLLD. BLL Review, 4, 31-36.

British Library Document Supply Centre \& Canada Institute for Scientific and Technical Information. (1996). A comparative study of access to journals through subscriptions and document delivery. Retrieved December 16, 2003, from http://www.icsti.org/icsti/comparative.html Bunn, R.M. (1957). Planning a national lending library for science and technology. Aslib Proceedings, 9, 280-288.

Bunn, R.M. (1958). The National Lending Library for Science and Technology—1958. Aslib Proceedings, 10, 251-256.

Bunn, R.M. (1962). Binding of periodicals in the National Lending Library. Journal of Documentation, 18, 20-24. 
Camic, C., \& Xie, Y. (1994). The statistical turn in American social science: Columbia University, 1890-1915. American Sociological Review, 59, 773-805.

Cattell, J.M. (1906). A statistical study of American men of science. Science, 24, 658-665; 699-707; 732-742.

Cattell, J.M. (1910). A further statistical study of American men of science. Science, 32, 633-648; 672-688

Clarke, A. (1981). The use of serials at the British Library Lending Division in 1980. Interlending Review, 9, 111-117.

Cochran, W.G. (1954). Some methods for strengthening the common $\chi^{2}$ tests. Biometrics, 10, 417-451.

Coleman, J.S. (1964). Introduction to mathematical sociology. New York: The Free Press of Glencoe.

Eggenberger, F., \& Pólya, G. (1923/1984). Über die Statistik verketteter Vorgänge. In G. Pólya (Ed.), Probability; combinatorics; teaching and learning in mathematics (pp. 94-104). Collected papers of G. Pólya (Vol. 4). Mathematicians of our time (Vol. 22). Cambridge, MA: MIT Press.

Ehrenberg, A.S.C. (1959). The pattern of consumer purchases. Applied Statistics, 8, 26-41.

Elliott, J.M. (1977). Some methods for the statistical analysis of samples of benthic invertebrates (2nd ed.). Freshwater Biological Association scientific publication, no. 25. Ambleside, England: Freshwater Biological Association.

Evans, G.E., \& Zarnofsky, M.R. (2000). Developing library and information center collections (4th ed.). Library and information science text series. Englewood, CO: Libraries Unlimited.

Feller, W. (1943). On a general class of "contagious" distributions. Annals of Mathematical Statistics, 14, 389-400.

Fisher, A. (1922). The mathematical theory of probabilities and its application to frequency curves and statistical methods: Vol. 1. Mathematical probabilities, frequency curves, homograde and heterograde statistics (2d ed., C. Dickson \& W. Bonynge, Trans.). New York: Macmillan.

Fisher, R.A. (1925). Statistical methods for research workers. Biological monographs and manuals, No. 5. Edinburgh: Oliver and Boyd.

Fussler, H.H., \& Simon, J.L. (1969). Patterns in the use of books in large research libraries. Chicago: University of Chicago Press.

Galton, F. (1874). English men of science: Their nature and nurture. London: Macmillan.

Galton, F. (1892/1925). Hereditary genius: An inquiry into its laws and consequences (2nd ed.). London: Macmillan.

Greenwood, M., \& Yule, G.U. (1920). An inquiry into the nature of frequency distributions representative of multiple happenings with particular reference to the occurrence of multiple attacks of disease or of repeated accidents. Journal of the Royal Statistical Society, 83, 255-279.

Griffiths, D.A. (1973). Maximum likelihood estimation for the betabinomial distribution and an application to the household distribution of the total number of cases of a disease. Biometrics, 29, 637-648.

Haight, F.A. (1967). Handbook of the Poisson distribution. Publications in operations research, No. 11. New York: Wiley.

Haight, F.A. (1978). Special discrete distributions. In W.H. Kruskal \& J.M. Tanur (Eds.), International encyclopedia of statistics (Vol. 1, pp. 155161). New York: Free Press.

Houghton, B. (1972). Out of the dinosaurs: The evolution of the National Lending Library for Science and Technology. The management of change: studies in the evolution of library systems, 1. London: Clive Bingley.

Johnson, N.L., \& Kotz, S. (1969). Discrete distributions. Distributions in statistics. Boston: Houghton Mifflin.

Katz, B., \& Katz, L.S. (Eds.). (2000). Magazine for libraries (10th ed.). New Providence, NJ: Bowker.

Keynes, J.M. (1921). A treatise on probability. London: Macmillan.

Kosko, B. (1993). Fuzzy thinking: The new science of fuzzy logic. New York: Hyperion.

Kurth, W.H. (1962). Survey of the interlibrary loan operation of the National Library of Medicine. Washington, DC: U.S. Department of Health, Education, and Welfare, Public Health Service.

Line, M.B., \& Sandison, A. (1974). "Obsolescence" and changes in the use of literature with time. Journal of Documentation, 30, 283-350.
Line, M.B., \& Scales, P.A. (1976). Mr. Line and Ms. Scales write. Journal of Documentation, 32, 322.

Line, M.B., \& Steemson, R.J. (1977). Comparisons of ranked lists of journals. Journal of Documentation, 33, 151-153.

Line, M.B., \& Wood, D.N. (1975). The effect of a large-scale photocopying service on journal sales. Journal of Documentation, 31, 234-235.

Merry, K., \& Palmer, T. (1984). Use of serials at the British Library Lending Division in 1983. Interlending and Document Supply, 12, 56-60.

Moran, P.A.P. (1968). An introduction to probability theory. Oxford: Clarendon Press.

Moroney, M.J. (1956). Facts from figures (3rd ed.). Baltimore, MD: Penguin Books.

Newbold, E.M. (1927). Practical applications of the statistics of repeated events, particularly to industrial accidents. Journal of the Royal Statistical Society, 90, 487-547.

Patil, G.P., \& Joshi, S.W. (1968). A dictionary and bibliography of discrete distributions. New York: International Statistical Institute/Hafner.

Pearson, E.S., \& Hartley, H.O. (Eds.). (1966). Biometrika tables for statisticians (Vol. 1). Cambridge: Cambridge University Press.

Pearson, K. (1894). Contributions to the mathematical theory of evolution. Philosophical Transactions of the Royal Society of London, A(185), 71-110.

Pearson, K. (1895). Contributions to the mathematical theory of evolution, II: Skew variation in homogeneous material. Philosophical Transactions of the Royal Society of London, A(186), 343-414.

Pearson, K. (1900). On the criterion that a given system of deviations from the probable in the case of a correlated system of variables is such that it can be reasonably supposed to have arisen from random sampling. The London, Edinburgh, and Dublin Philosophical Magazine and Journal of Science, 50(5th Series), 157-175.

Pearson, K. (1901). Mathematical contributions to the theory of evolution, $\mathrm{X}$ : Supplement to a memoir on skew variation. Philosophical Transactions of the Royal Society of London, Series A(197), 443-459.

Pearson, K. (1916). Mathematical contributions to the theory of evolution, XIX: Second supplement to a memoir on skew variation. Philosophical Transactions of the Royal Society of London, Series A(216), 429-457.

Price, A.L., \& Carey, K.R. (1993). Serials use study raises questions about cooperative ventures. Serials Review, 19, 79-84.

Price, D.J. de Solla. (1963). Little science, big science. New York: Columbia University Press.

Price, D.J. de Solla. (1976). A general theory of bibliometric and other cumulative advantage processes. Journal of the American Society for Information Science, 27, 292-306.

Pritchard, A. (1969). Statistical bibliography or bibliometrics? Journal of Documentation, 25, 348-349.

Rietz, H.L. (1924). Bernoulli, Poisson, and Lexis distributions. In H.L. Rietz (Ed.), Handbook of mathematical statistics (pp. 82-91). Boston: Houghton Mifflin.

Rietz, H.L. (1927). Mathematical statistics. The Carus mathematical monographs, No. 3. Chicago: Mathematical Association of America/Open Court.

Scales, P.A. (1976). Citation analyses as indicators of the use of serials: A comparison of ranked title lists produced by citation counting and from use data. Journal of Documentation, 32, 17-25.

Snedecor, G.W., \& Cochran, W.G. (1989). Statistical methods (8th ed.). Ames: Iowa State University Press.

Stewart, B. (1976). The optimum size for periodical collections in liberal arts college libraries. In D. Gore (Ed.), Farewell to Alexandria: Solutions to space, growth, and performance problems of libraries (pp. 105-121) Westport, CN: Greenwood Press.

"Student." (1907). On the error of counting with a haemacytometer. Biometrika, 5, 351-360.

"Student." (1919). An explanation of deviations from Poisson's Law in practice. Biometrika, 12, 211-215.

Urquhart, D.J. (1957). The National Lending Library for Science and Technology. Journal of Documentation, 13, 13-31.

Urquhart, D.J. (1959a). Use of scientific periodicals. In Proceedings of the International Conference on Scientific Information, Washington, DC, November 16-21, 1958 (Vol. 1, pp. 287-312). Washington, DC: National Academy of Sciences, National Research Council. 
Urquhart, D.J. (1959b). The U.K. National Lending Library for Science and Technology. Unesco Bulletin for Libraries, 13, 173-175.

Urquhart, D.J. (1960). The National Lending Library for Science and Technology (N.L.L.). In Proceedings, papers and discussions at the Scarborough Conference (pp. 51-59. London: Library Association.

Urquhart, D.J. (1962). Plain man's guide to the National Lending Library for Science and Technology. Library Association Record, 64, 319-322.

Urquhart, D.J. (1963). Review of the book survey of the interlibrary loan operation of the National Library of Medicine by William H. Kurth. Journal of Documentation, 19, 86-87.

Urquhart, D.J. (1977). Urquhart's law. Journal of Documentation, 33, 149.

Urquhart, D.J. (1981). The principles of librarianship. Metuchen, NJ: Scarecrow Press.

Urquhart, D.J. (1986). Librarianship is an experimental science. In G.G. Allen \& F.C.A. Exon (Eds.), Research and the practice of librarianship: An international symposium (pp. 21-28). Western library studies, 7. Perth: The Library, Western Australian Institute of Technology.

Urquhart, D.J. (1990). Mr. Boston Spa. Leeds, England: Wood Garth.

Urquhart, D.J., \& Bunn, R.M. (1959). A national loan policy for scientific serials. Journal of Documentation, 15, 21-37.
Urquhart, J.A. (1977). The application of BLLD use data to the relegation of periodicals. Aslib Proceedings, 29, 32-34.

Urquhart, J.A. (1978). Relegation. In P. Mayes (Ed.), Periodicals administration in libraries: A collection of essays (pp. 116-126). London: Clive Bingley.

Urquhart, J.A. (1982). Has Poisson been kicked to death? - a rebuttal of the British Library Lending Division's views on the inconsistency of rank lists of serials. Interlending Review, 10, 97-100.

Urquhart, J.A., \& Urquhart, N.C. (1976). Relegation and stock control in libraries. Stocksfield, England: Oriel Press.

Weldon, W.F.R. (1890). The variations occurring in certain Decapod Crustacea, I: Crangon vulgaris. Proceedings of the Royal Society of London, 47, 445-453.

Weldon, W.F.R. (1893). On certain correlated variations in Carcinus moenas. Proceedings of the Royal Society of London, 54, 318-329.

Winsor, C.P. (1947). Das Gesetz der kleinen Zahlen. Human Biology, 19, 154-161.

Wood, J.L. (1969). A review of the availability of primary scientific and technical documents with the United States (Vols. 1-3). Washington, DC: U.S. Department of Health, Education, and Welfare, Office of Education, Bureau of Research. 